University of Louisville

ThinkIR: The University of Louisville's Institutional Repository

Electronic Theses and Dissertations

$5-2019$

\title{
A contemporary trend analysis of Kentucky State Police vehicular pursuit-related collisions and injuries.
}

Frederick A. Williams Jr.

University of Louisville

Follow this and additional works at: https://ir.library.louisville.edu/etd

Part of the Law Enforcement and Corrections Commons

\section{Recommended Citation}

Williams, Frederick A. Jr., "A contemporary trend analysis of Kentucky State Police vehicular pursuitrelated collisions and injuries." (2019). Electronic Theses and Dissertations. Paper 3205.

https://doi.org/10.18297/etd/3205

This Doctoral Dissertation is brought to you for free and open access by ThinkIR: The University of Louisville's Institutional Repository. It has been accepted for inclusion in Electronic Theses and Dissertations by an authorized administrator of ThinkIR: The University of Louisville's Institutional Repository. This title appears here courtesy of the author, who has retained all other copyrights. For more information, please contact thinkir@louisville.edu. 


\title{
A CONTEMPORARY TREND ANALYSIS OF KENTUCKY STATE POLICE VEHICULAR PURSUIT-RELATED COLLISIONS AND INJURIES
}

\author{
By \\ Frederick A. Williams Jr. \\ B.S., Tennessee State University, 1995 \\ M.S., University of Louisville, 2000

\begin{abstract}
A Dissertation
Submitted to the Faculty of the

College of Arts and Sciences of the University of Louisville in Partial Fulfillment of the Requirements

for the Degree of
\end{abstract} \\ Doctor of Philosophy in Criminal Justice \\ Department of Criminal Justice \\ University of Louisville \\ Louisville, Kentucky
}

May 2019 



\title{
A CONTEMPORARY TREND ANALYSIS OF KENTUCKY STATE POLICE VEHICULAR PURSUIT-RELATED COLLISIONS AND INJURIES
}

\author{
By
}

Frederick A. Williams Jr.

B.S., Tennessee State University, 1995

M.S., University of Louisville, 2000

A Dissertation Approved on

April 18, 2019

By the following Dissertation Committee:

Dissertation Chair

Dr. George E. Higgins

Dr. Viviana Andreescu

Dr. Gennaro F. Vito

Dr. George Richards 


\section{DEDICATION}

This dissertation is dedicated to my mother

\section{Marguerite R. Williams}

who went to be with the Lord on January 15, 2018. 


\section{ACKNOWLEDGEMENT}

First, I am truly indebted and thankful to Dr. George E. Higgins for his support and guidance over the years. Dr. Higgins has been a mentor and a friend. Dr. Higgins also served as my dissertation chair and guided me through this process. I owe much of my success to Dr. Higgins and his expertise in academia. Dr. Higgins was always supportive, positive and cool under pressure. I would also like to thank my dissertation committee members, Dr. Vivian Andreescu, Dr. Anthony Vito and Dr. George Richards for their insight and support. Special thanks Dr. Andreescu who has been supportive throughout my academic career. Finally, I would like to thank my family, Stephanie R. Williams (wife), Anna R. Williams (daughter), Alayna R. Williams (daughter) and Frederick A. Williams Sr. (father). I am extremely thankful to have such a loving and supportive family unit. 


\begin{abstract}
A CONTEMPORARY TREND ANALYSIS OF KENTUCKY STATE POLICE VEHICULAR PURSUIT-RELATED COLLISIONS AND INJURIES
\end{abstract}

Frederick A. Williams Jr.

May 10, 2019

This study investigates the trends in vehicular pursuits conducted by the Kentucky State Police (KSP) over time (i.e., years 2009 - 2017). Additionally, predictors for collisions and injuries were examined. The issues surrounding vehicular pursuits center on officer safety and agency liability concerns with the most significant of these being collisions and injuries.

This study contains several primary areas. Chapter two includes a review of the literature surrounding the area of vehicular pursuits. Specifically, it reviews definitions pertinent to this study, legal aspects concerning pursuits, major empirical studies conducted on pursuits and specific risks associated with pursuit practices. This section was utilized to develop the themes for analysis. Chapter three covered the methodology for this study. In this chapter, the measures for analysis were presented and the analysis plan was thoroughly explained. The analysis plan involved three steps: Step 1: Descriptive Statistics; Step 2: Trend Analysis and Step 3: Logistic Regressions. The trend analysis employs a Bayesian process utilized by the Center for Disease Control and Prevention (CDC). This process is used to examine risk behaviors over time and was 
ideal for conducting the type of analysis required for this study. Chapters 4 presents the results of this study. The results indicate an upward trend in pursuit-related collisions and injuries between 2009 and 2017. The results determined that pursuits involving three or more units had the potential to increase the likelihood of collisions while the use of tire deflation devices was found to decrease the risk of collisions. No predictors were found significant for injuries.

Chapter 5 contains the discussion, policy recommendations, study limitations, recommendations for future studies and conclusions. The policy recommendations should be generalizable across law enforcement agencies of similar disposition to the KSP. Recommendations are presented in the areas of intervention techniques, pursuit policy development, compliance with pursuit policy, and the development of pursuit training programs. Lastly, this study concludes with limitations and conclusions which focus on suggestions for improvement and provisions for making any future studies conducted on KSP pursuit data more robust. 
TABLE OF CONTENTS

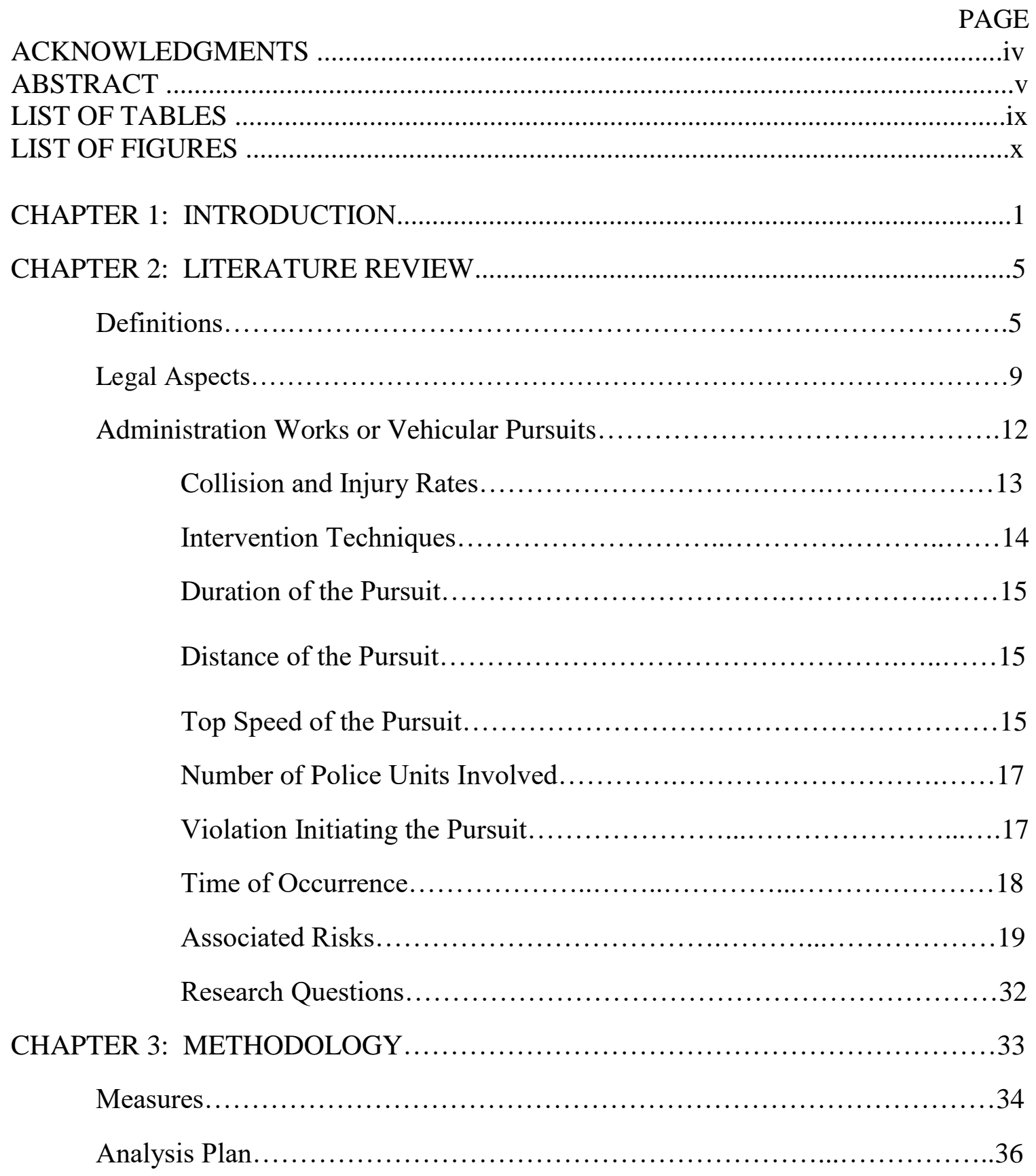




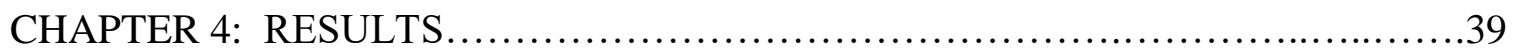

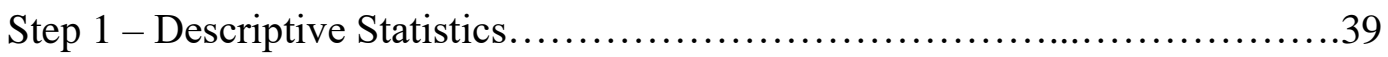

Step 2 - Trend Analysis...........................................42

Step 3 - Logistic Regression.........................................44

CHAPTER 5: DISCUSSION .............................................. 47

Trends.................................................................. 47

Predictors......................................................47

CHAPTER 6: POLICY RECOMMENDATIONS ................................49

Annual Pursuit Evaluation.................................................50

Proper Pursuit Mentality.............................................50

Decision-Making.................................................. 51

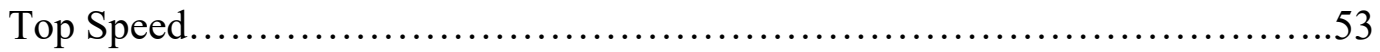

Officer Distraction.................................................52

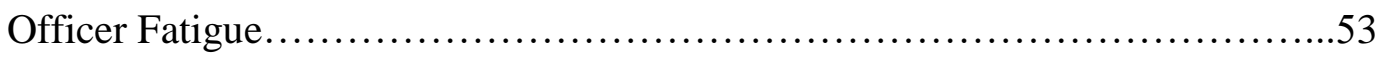

Pursuit Intervention Techniques and Technology...........................54

Developing Effective Pursuit Policy.....................................59

Compliance with Pursuit Policy........................................62

Developing and Effective Pursuit Training Program........................64

CHAPTER 7: LIMITATIONS AND FUTURE STUDIES .......................67

CHAPTER 8: CONCLUSION............................................69

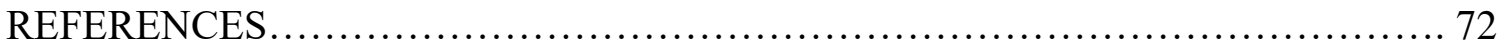

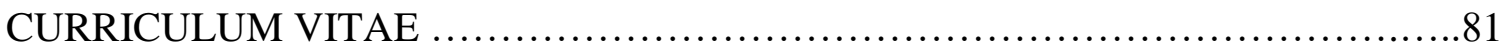




\section{LIST OF TABLES}

TABLE

PAGE

1. Descriptive Statistics........................................................... 40

2. Trends in Pursuit-related Collisions................................................43

3. Trends in Pursuit-related Injuries............................................43

4. Model 1 - Logistic Regression - Pursuit-Related Collisions........................45

5. Model 2 - Logistic Regression - Pursuit-Related Injuries..........................46 


\section{LIST OF FIGURES}

FIGURE

PAGE

1. KSP Trends in Pursuit-related Collisions and Injuries..........................44 


\section{CHAPTER 1}

\section{INTRODUCTION}

Police vehicular pursuits are currently understudied. The risk associated with pursuits remains one of the topmost pressing concerns for a law enforcement agency. Of those risks, pursuit-related collisions (i.e., collisions) and the resulting pursuit-related injuries (i.e., injuries) remain a chief liability concern for law enforcement agencies (Kappeler, 2006). Collisions are as much an officer's safety concern as they are a public safety concern for the Kentucky State Police (KSP). Historically, fifteen (48.3\%) of the thirty-one (31) Fallen KSP Troopers died as a result of a collision involving a vehicle. Eight (8) were the result of emergency response driving and one (1) fatality involved a pursuit-related collision (KSP, 2018). While the KSP collects pursuit data annually, a trend analysis of this data has not been conducted to examine trends across a large span of years. This type of analysis will be useful to administration and academia in understanding the current state of pursuit operations, officer safety and any potential liability concerns requiring attention.

Traffic collisions are the leading cause of death for law enforcement officers (LEOs) (Gustafson, 2015). Each collision and resultant damage, injury or fatality has a cost. As stated in a 2010 estimate, each officer fatality costs approximately $\$ 1.7$ million (Gustafson \& Cappitelli, 2010). This does not include the emotional toll stemming from the loss. President Obama's Task Force on $21^{\text {st }}$ Century Policing (2015) conducted a review of law enforcement fatalities over the last two decades. This report also 
concluded that more LEOs were killed by traffic collisions than by firearms (National Law Enforcement Officers Memorial Fund, 2014). This is consistent with the KSP data. Historically, thirteen (13) (41.9\%) of thirty-one (31) troopers were killed from gunfire (KSP, 2018). Further, Wolfe, Rojek, Alpert, Tiesman, and James (2015) stated that for every LEO traffic-related fatality, more than 200 other LEOs are injured in collisions. The National Highway Traffic Safety Administration (NHTSA) (2011) reported that pursuit-related officer deaths increased between 1980 and 2008. Some authors suggest that as much as 40 percent of pursuits end in collisions (Alpert \& Anderson, 1996; Auten, 1994; Falcone, Wells, \& Charles, 1992). Also, there are around 300 deaths involving bystanders, suspects or the police which occur annually because of pursuits (Masters et al., 2011). As evidenced by these statistics, collisions clearly present a significant officer safety, public safety, and agency liability concern.

Today, many law enforcement agencies, especially urban departments, have begun to move away from allowing their LEOs to engage in vehicular pursuits. Many local agencies have enacted restrictive policy prohibiting pursuits due to the dangers involved and liability concerns over this practice. Eighty-five $(85 \%)$ percent of local agencies, seventy-three (73\%) percent of sheriff's offices and only thirty-seven (37\%) of state police and highway patrol agencies had restrictive pursuit policy (LEMAS, 2013; Reaves, 2017). These restrictive policies often place limitations on when and how to pursue such as only permitting vehicular pursuits for certain offenses or in certain circumstances. State police and highway patrol agencies are among the last holdouts regarding the establishment of extremely restrictive pursuit policy but even they have developed comprehensive policies to protect their agencies, troopers and the public. 
Currently, the decision to pursue is left to the LEO in about thirty (30\%) percent of state police and highway patrol agencies as compared to seventeen (17\%) percent of sheriffs' offices and thirteen (13\%) of local police departments (LEMAS, 2013; Reaves, 2017).

Likewise, academic research has become aware of the collision risks associated with pursuits. Most of the academic research conducted on pursuits addresses the danger involved and potential ramifications thereof (Hicks, 2006). For instance, 6,000 fatal collisions occurred between 1996 and 2015. This means on average about 355 people die as a result of collisions annually. The number of fatalities seemed to peak at round 400 annually during 2006 and 2007 (Reaves, 2017). Many of the risk factors related to pursuit-related collisions will be examined thoroughly within this study.

Vehicular pursuits are filled with difficult decisions for any LEO involved. The decision to initiate and/or continue a pursuit can be difficult for a variety of reasons including concerns over policy, liability and public safety. This study will be accomplished in three primary stages. First, a review of the literature encompassing vehicular pursuits, pursuit-related collisions, risk factors, pursuit law and legal liability, and factors contributing to pursuit-related collisions. Second, a quantitative analysis will be conducted utilizing KSP pursuit data collected from the KSP between the years of 2009 to 2017 . The primary means of examination will be trend analysis of the collisions and injuries occurring over the time span of this dataset. Further, analysis will be conducted to gain an understanding of the correlates of these collisions and injuries. Lastly, findings and limitations will be presented, policy recommendations will be made, and conclusions will be drawn. 
It is important to understand all aspects of vehicle pursuits and the factors surrounding them. The literature review will address each of the areas mentioned previously in detail. 


\section{CHAPTER 2}

\section{LITERATURE REVIEW}

\section{$\underline{\text { Definitions }}$}

To properly examine vehicular pursuits, it is essential that a clear definition of a vehicular pursuit, pursuit-related collision, and pursuit-related injury be established. It may seem easy to classify all police chases as pursuits, but pursuits must meet certain criteria before they are officially classified as a vehicular pursuit. Several definitions are available to clarify the criteria. Nugent, Connors, McEwen, \& Mayo (1990) noted that any pursuit definition should include these four components: 1) Any pursuing law enforcement officer should be in a patrol vehicle clearly identified as a patrol vehicle; 2) The suspect should be clearly aware of the officer's intention for them to stop and fail to comply with these instructions; 3 ) the rationale for the pursuit may include traffic or criminal violations; 4) vehicle speed may vary throughout the duration of the pursuit.

Multiple definitions of pursuits encompass these different aspects. For instance, Alpert and Anderson (1986) defined vehicular pursuits as "an active attempt by a law enforcement officer operating an emergency vehicle to apprehend alleged criminals in a moving motor vehicle, when the driver of the vehicle, in an attempt to avoid apprehension, significantly increases his or her speed or takes other evasive action." (Alpert \& Anderson, 1986, p. 5). NHTSA defines police pursuit as follows: 
A police pursuit is defined as an event initiated by a law enforcement officer operating an authorized motor vehicle giving notice to stop (either through the use of visual or audible emergency signals or a combination of emergency devices) to a motorist who the officer is attempting to apprehend, and that motorist fails to comply with the signal by either maintaining his/her speed or taking evasive action to elude the officer's attempt to stop the motorist. A pursuit is terminated when the motorist stops, the attempt to apprehend is discontinued by the officer, or at the direction of a competent authority. A police pursuit related death is defined as all fatalities recorded in a pursuit related crash. (Hutson, Rice, Chana, Kyriacou, Chang, \& Miller, 2007, p. 279).

Nugent et al. (1990) define vehicular pursuit as the following:

An active attempt by a law enforcement officer on duty in a patrol car to apprehend one or more occupants of a moving motor vehicle, providing the driver of such vehicle is aware of the attempt and is resisting apprehension by maintaining or increasing his speed or by ignoring the law enforcement officer's attempt to stop him (Nugent et al., 1990, p.1).

Although very similar to the Nugent et al. (1990) vehicular pursuit definition, the NHTSA (2004) definition will be adopted for the purposes of this study. This definition is preferred because it offers a more complete depiction of the characteristics of most pursuits; also, it is better aligned with operations within the KSP.

The NHTSA (2004) definition contains several characteristics which are important to include in any pursuit definition. First, they specifically use the "authorized motor vehicle" (Hutson et al., 2007, p. 279). This is important because pursuits should 
not be initiated by any LEO who is not driving an authorized motor vehicle. When pursuits are initiated by LEOs in vehicles that are not easily distinguishable as marked patrol vehicles, the suspect may claim that they were not certain they were being subjected to a lawful stop as justification for not complying. Second, NHTSA (2004) uses the phrase "giving notice to stop (either through the use of visual or audible emergency signals or a combination of emergency devices)" (Hutson et al., 2007, p. 279). KSP policy requires the use of both audible and visual indicators during a pursuit. Lastly, NHTSA (2004) included the phrase "motorist fails to comply with the signal by either maintaining his/her speed or taking evasive action to elude the officer's attempt to stop the motorist." (Hutson et al., 2007, p. 279). This is also important because if the suspect begins to slow, they can make an argument that they were preparing to stop or intended to stop. Conversely, if the suspect maintains or increase their speed or takes an evasive action, no such argument can be made. This is also important in articulating that a pursuit occurred. The LEO and/or the prosecution must be able to establish that the suspect was aware of the LEO's intent to stop them and consciously ignored their attempts. For these reasons, the NHTSA (2004) definition is considered more complete than Alpert and Anderson (1986).

For this study, negative outcomes are considered pursuit-related collisions and pursuit-related injuries. Pursuit-related collisions will be referred to as collisions and pursuit-related injuries will be referred to as injuries. Collisions and injuries may be referenced separately in this study however these terms are not considered independent of one another. Collision often result in injuries and injuries rarely occur without collisions. 
Collisions are defined as any collision involving any participants of a vehicular pursuit as defined by NHTSA (2004). NSC (2007) provides the following definition for collision accident:

A collision accident is a road vehicle accident other than an overturning accident in which the first harmful event is a collision of a road vehicle in-transport with another road vehicle, other property or pedestrians (p. 35).

The NSC definition will be utilized for this study because it excludes the requirement that the characteristics of the collision include "resulting in injuries, death and/or loss of property" (p. 26). This is not a requisite for this study which only requires that the first harmful event occur. Collisions as referenced in this study, do not include legal intervention which occurs when a LEO intentionally drives their patrol vehicle into the suspect vehicle with the intent to terminate the pursuit. NSC (2007) defines legal intervention as: "Legal intervention is a category of deliberate intent in which the person who acts or refrains from acting is a law-enforcing agent or other official" (p. 18). Further, this definition falls in agreement with KSP pursuit policy.

Injuries are considered any injury resulting from a vehicular pursuit as defined by NHTSA (2004). These injuries may be sustained by the suspect operating the vehicle being pursued, by the pursuing LEO, a passenger in either the pursuit vehicle or vehicle being pursued or an uninvolved by-stander. NSC (2007) defines injury as: "An injury is bodily harm to a person" (p. 16). Injury also includes fatal injury and fatality. NSC (2007) defines fatal injury as: "A fatal injury is any injury that results in death" (p. 17). Fatality is defined as “....any death resulting from a fatal injury” (NSC, 2007, p. 17). Both definitions will serve as the basis for this study. 


\section{$\underline{\text { Legal Aspects }}$}

In addition to safety concerns, liability stemming from pursuit-related collisions are a major concern to law enforcement agencies. For this reason, it is also important to examine the laws related to vehicle pursuits and legal liability. Most jurisdictions recognize violations of traffic law as prima facie proof of negligence (Kappler, 2006). Others justify a pursuit based upon the circumstances classifying it as an emergency. However, for purpose of immunity for the LEO, some courts do not see the violation of the law or potential violation of a law as an emergency for the purposes of justifying the pursuit. Consequently, police negligence is determined by the circumstance surrounding the LEOs violation of a traffic regulation, their use of the pursuit vehicle and the severity of the suspect's offense. The Michigan Supreme Court ruled in Fisher v. City of Ann Arbor (1983) that for statutory immunity to apply, the LEO must reasonably believe an emergency exists. The California Supreme Court in Kisbey v. California (1984) added further credence to the argument for immunizing the police for involvement in pursuits. Regardless of numerous and varied decision of state courts, often time's the potential for legal liability exists, and litigation ensues (Kappler, 2006).

In situations where LEOs are not afforded sovereign discretionary, or statutory immunity, the idea of negligence is often used by state courts to determine liability. Negligence is established by proving the existence of a duty and observing that this duty has been breached (Kappler, 2006). Under these circumstances, the principles of duty, breach of duty and proximate cause are applied to policing situation where injury occurs. The use of negligence theory has resulted in the emergence of principles of law on police liability for negligence in the operation of emergency vehicles. The principles are very 
similar to the requirements of negligence. They are: 1) duty of care; 2) breach of reasonableness; 3) proximate cause; and 4) actual injury or damage (Kappler, 2006).

Legal liability not only stems risk but also from potential violations of the constitutional rights of the suspect being pursued. When these types of constitutional violations occur, legal remedies may be pursued. This may result in a lawsuit in which a law enforcement agency may be found at fault and required to pay a substantial penalty.

Certain constitutional amendments have been deemed to pertinent to police vehicular pursuits. Specifically, the $4^{\text {th }}$ and $14^{\text {th }}$ amendments have been found to be independently applicable in such cases involving pursuits. The application of the $4^{\text {th }}$ Amendment to vehicular pursuits was addressed in Brower v. County of Inyo (1989). Brower was involved in a high-speed pursuit while driving a stolen vehicle. Brower subsequently crashed into a police roadblock with claimed his life. In this case, it was determined that when a LEO initiates a pursuit, it does not constitute a seizure under the $4^{\text {th }}$ Amendment. Similarly, the Supreme Court ruled that the termination or intent to terminate an individual's freedom of movement by a governmental entity does not constitute a violation of their $4^{\text {th }}$ Amendment protections (Hicks, 2006; Pipes \& Pape, 2001).

The $14^{\text {th }}$ Amendment protects against deprivation of a person's life, liberty, or property, without due process of law or equal protection under the law (Kappeler, Kappeler, \& Del Carmen, 1993). Some $14^{\text {th }}$ Amendment issues were addressed in County of Sacramento v. Lewis (1998). In this case, a 16-year-old Philip Lewis was riding as a passenger on a motorcycle driven by 18 -year-old Brian Willard. Willard committed a traffic violation and fled from a Sacramento County Sheriff's Deputy when 
they attempted to stop Willard. A pursuit ensued which reached speeds of $100 \mathrm{mph}$. The pursuit ended with Willard causing the motorcycle to tip over and Lewis being struck and killed by the pursuing patrol vehicle. The litigants claimed that the cyclist's due process was violated during the high-speed pursuit through deliberate and reckless indifference to life. The Ninth Circuit Court ruled the deputy was not liable for Lewis' death by showing "deliberate indifference" and that a violation of the $14^{\text {th }}$ Amendment had not occurred because there was no intent to cause harm separate from the legitimate intent to effect an arrest (Hess, Orthmann, \& Cho, 2014; Pipes \& Pape, 2001).

The Supreme Court applied the "shocks-the-conscience" test to pursuit cases for more than a half a century. Rochin v. California (1952) was established as the benchmark case for this standard. The Supreme Court recognized that LEOs are not responsible for pursuits and therefore are not responsible for collisions that result from them. They ruled that the blame lied with the fleeing suspect who created the dangerous situation by failing to stop when instructed and fleeing from the police (Hess et al., 2014). In addition to constitutional concerns, considerable legal liability lies in the manner and type of force used to end a pursuit. Patrol vehicles are large heavy pieces of machinery capable of traveling at very high speeds. Virtually any use of the patrol vehicle to physically stop a fleeing suspect can be argued as employing the use of deadly force. The use of potentially deadly force by the police to end a pursuit was solidified by the Supreme Court in Scott v. Harris (2007). In this case, the Supreme Court relied heavily on in-car camera video evidence. The facts of this case involve Deputy Scott's decision to ram the rear of Mr. Harris vehicle causing it to travel down an embankment. This resulted in Mr. Harris, who was 19 years old at the time of the accident, becoming a 
quadriplegic. Harris sued claiming Scott's actions caused his paralysis and violated his constitutional rights. Scott countered by claiming that his actions were warranted due to the danger imposed on the public by Mr. Harris' reckless actions while operating his vehicle. While the Supreme Court ruled in favor of Scott, this decision does not protect LEOs from being sued civilly under state statutes for wrongful death (Hess et al., 2014).

The next section will examine the themes in the literature which impact pursuitrelated collisions and injuries. Themes identified in the literature and present within the data set may be utilized in the statistical analysis.

\section{$\underline{\text { Administrative Works of Vehicular Pursuits }}$}

To gain a proper perspective on vehicle pursuits, it is necessary to examine some of the most well know empirical studies conducted in this area with administrative data. These studies are considered seminal works in area of pursuit literature: the California Highway Patrol study of 1982 (Beckman, 1983); Michigan State University study of 1984 (Payne \& Fenske, 1997); the Miami-Metro Dade County Pursuit study (Alpert \& Dunham, 1990); the Police Pursuit Driving Operations study in Illinois (Auten, 1991); and the Illinois State University study (Charles, Falcone \& Wells, 1992). This section will examine the overarching themes regarding pursuit-related collisions and injuries from these and other studies. Some of these themes will be utilized as measures for this study.

The methodology and findings from each of these studies are similar in nature. They each range from six months to three years in duration. The frequency of pursuits that occurred during the period under observation ranged from 286 to 952 with the 
majority initiated as the result of a traffic stop. The following themes were identified in the literature: collision and injury rates, the number or police units involved, the top speed of the pursuit, the duration of the pursuit, the distance of the pursuit, the violation initiating the pursuit, the time of occurrence and intervention techniques used.

\section{Collision and Injury Rates}

Several studies examined the collision and injury rates of pursuits. The rates of collision and injury were relatively consistent between studies. In the California Highway Patrol (CHP) study, Beckman (1983) found collisions to have occurred in thirty (30\%) percent of the pursuits and injuries occurred eleven (11\%) percent of the time (Beckman, 1983). In another study utilizing a modified version on the CHP questionnaire, Beckman (1986) found the collision rate to be forty-two (42\%) percent with a fourteen (14\%) percent injury rate. Three (3\%) percent of the injuries were fatalities. Alpert and Dunham (1990) identified an collision rate of thirty-three (33\%) percent and an injury rate of seventeen (17\%) percent in the Miami-Metro Dade County Pursuit study of 1986. Of those injuries, thirty injuries were incurred by the police, seventeen injuries by innocent bystanders and one hundred and thirteen injuries were incurred by the fleeing suspect or occupants. Less than one percent $(0.7 \%)$ were fatalities (Alpert \& Dunham, 1990). Auten (1991) established a collision rate of twenty-six (26\%) percent and an injury rate of nine (9\%) percent in the Police Pursuit Driving Operations study of 1990 in Illinois. No fatalities were reported in this study (Auten, 1991). The Illinois State University study found a collision rate of thirty-four (34\%) percent and an injury rate of seventeen (17\%) percent. Two (2\%) percent of the injuries were fatalities 
(Charles, Falcone \& Wells, 1992). In the Police Pursuits in an Age of Innovation and Reform study, Yates (2009) concluded that pursuits ended in collision twenty-three (23\%) percent of the time. Nine (9\%) percent of these pursuits ended with an injury to the LEO, the suspect or an innocent bystander (Yates, 2009). Alpert and Fridell (1992) found that pursuits ended with a collision forty-four (44\%) percent of the time in the Minnesota study. They also cited twenty-four (24\%) percent of those collisions involved injury. In sum, the reviewed studies found that the about twenty-three (23\%) percent to forty-four (44\%) percent of pursuits ended in collisions. The percent of collisions that resulted in injuries varied from nine (9\%) percent to twenty-four (24\%) percent. Only point seven $(0.7 \%)$ percent to three $(3 \%)$ percent of these injuries resulted in a fatality.

\section{Intervention Techniques}

The use of pursuit intervention techniques to end a pursuit has the potential for negative outcomes. Some intervention techniques place pursuit vehicles and LEOs in proximity to the suspect vehicle and increase the chances for collisions and injuries. Yates (2009) found that pursuits were ended by employing tire deflation devices in threepoint four (3.4\%) percent of the pursuits (Yates, 2009). In general, empirical studies that examined the circumstances and the risk factors associated with collisions and injuries did not consider the role played by various intervention techniques used by LEOs. However, intervention techniques such as the use of tire deflation devices and rolling blocks may be a point of examination in the study based upon the variance presented in the KSP data set. 


\section{Duration of the Pursuit}

The duration of a pursuit may have an impact on the negative outcomes. Three studies examined the duration of pursuits. Beckman (1983) concluded that pursuits were often two minutes or less. Payne and Fenske (1997) found that most pursuits took place over short durations. In an Analysis of the IACP Report: 'Police Pursuits in an Age of Innovation and Reform, Yates (2009) found the average length of pursuits was five and a half minutes in duration. It can be deduced that pursuits of longer durations may be more likely to end in negative outcomes.

Distance of the Pursuit

The distance traveled during a pursuit may have a bearing on negative outcomes. There were two studies which addressed the distance of pursuits. In the Michigan State Police study, Payne and Fenske (1997) cited that most pursuits were shorter in distance. Similarly, Beckman (1983) found that most pursuits were approximately one mile in distance in California Highway Patrol study. Overall, it is believed that longer pursuits have a higher likelihood of ending with negative outcomes (Alpert, 1997).

Top Speed of the Pursuit

Pursuits which occurred at higher speeds were believed to have a higher likelihood for negative outcomes. This finding was confirmed in the National Institute of 
Justice (NIJ) publication, Police pursuit: policies and training (Alpert, 1997); the Analysis of the IACP Report: 'Police Pursuits in an Age of Innovation and Reform (Yates, 2009); Motor vehicle crash deaths related to police pursuits in the United States (Rivara and Mack, 2004); and the Emergency Vehicle Operator On-Board Device Distractions (Yager, Dinakar, Sanagaram \& Ferris, 2015).

Alpert (1997) specifically stated that the risk of negative outcomes was increased when speeds reached over 65 miles per hour (mph). Abdelwanis (2013) confirmed that pursuit speeds of $50 \mathrm{mph}$ and over are significantly associated with collisions. Similarly, Yates (2009) found the high speeds traveled during pursuits were identified as a correlate to injury. It was also determined that the average maximum speed of pursuits was 66 mph and most involved pursuit speeds exceeding 25 miles per hour over the speed limit (Yates, 2009). Rivara and Mack (2004) found that the characteristics of these collisions often included high speeds. Yager, Dinakar, Sanagaram, and Ferris (2015) suggested that the chances for risk of serious collisions is increased by being distracted while operating at high speeds while engaged in emergency response or pursuit driving.

Whether discussing a vehicular pursuit or standard operation of a police vehicle, certain factors have the potential to contribute to collisions. Operation at high rates of speed is one of those factors. LEOs receive driver training and operate a motor vehicle far more often than members of the public. Some consider them to be "professional drivers". Regardless of this fact, traveling at high speeds affect LEO in much the same way as it affects other motorists. The effect of speed on traffic collisions and fatalities is evident in several studies (Friedman, Hedeker, \& Richter, 2009; Garber and Gadiraju, 1992). The general thesis regarding speed is that higher speed limits lead to higher 
average speeds which results in higher collision rates and fatalities (Friedman et al., 2009; Gustafson, 2015). Simply stated, the greater the speed, the greater the likelihood of collisions and injuries.

\section{Number of Police Units Involved}

The number of police units involved in a pursuit may have a bearing on the potential for safety in pursuit-related collisions. Two studies address the number of units involved in the pursuit. Those studies are the Police pursuit: policies and training (Alpert, 1997) and California Highway Patrol study (Beckman, 1983). Alpert (1997) found the risk of collision and injury was greatly increased when more than one vehicle was involved in the pursuit. Beckman (1983) found that most pursuits involved at least two police units.

\section{Violation Initiating the Pursuit}

Some suggest a correlation between the violation initiating a pursuit and collisions and injuries. Therefore, it is important to examine which type of violations are the most often cited the reason a pursuit was initiated. Six studies were identified which concluded that traffic violations were the most cited reason for initiating a pursuit. Those studies are: the California Highway Patrol study of 1982 (Beckman, 1983); Michigan State University study of 1984 (Payne \& Fenske, 1997); Miami-Metro Dade County Pursuit study (Alpert \& Dunham, 1990); Police Pursuit Driving Operations in Illinois (Auten, 1991); Minnesota study (Alpert and Fridell, 1992); Illinois State University 
study (Charles, Falcone \& Wells, 1992); and the Police Pursuits in an Age of Innovation and Reform (Yates, 2009).

Further, Alpert and Dunham (1990) found that pursuits were initiated as a result of an observed traffic violation fifty-four (54\%) percent of the time. Two (2\%) percent were initiated for driving under the influence or reckless driving. Alpert and Fridell (1992) found traffic violations lead to pursuits in seventy-six (76\%) percent of the incidents. Driving under the influence initiated the pursuit in six (6\%) percent of these incidents. Yates (2009) found traffic offenses constituted the chief reason pursuits were initiated forty-two-point three $(42.3 \%)$ percent. The violation of suspicion of driving under the influence was cited fourteen-point nine (14.9\%) percent of the time. Seventytwo-point three $(72.3 \%)$ percent to KSP pursuits were initiated for traffic violations. The measure utilized in this study will narrow traffic violations to include any offense which presents a reasonable variance in the KSP data set. Additionally, driving under the influence and reckless driving will be examined as addressed in the literature.

\section{Time of Occurrence}

The time of day in which pursuits occur was examined in the literature by several scholars. Several research studies presented the time of day in relation to potential for collisions and injuries to occur. While this time of day was not available in the data set, it is important to mention as a potential risk factor in pursuit studies. Beckman (1983) concluded in the California Highway Patrol study most pursuits occurred at night. Rivara and Mack (2004) also found more collision occurring at dark. In the Michigan State University study of 1984, Payne and Fenske (1997) examined the collision rates of 
Michigan State Police (MSP) pursuits with on-duty MSP troopers and the general motoring public under different lighting conditions (i.e., daylight, darkness and dawn/dusk). These results also indicate that collision rates were significantly more likely during darkness and less likely to occur during daylight hours. Further, it was also found that more injuries occurred in daylight and darkness but not during dawn or dusk

light conditions. Fatalities were not found to be significant during any lighting condition other than darkness (Payne \& Fenske, 1997). Yates (2009) established the number of pursuits resulting in collisions was higher at dusk twenty-nine (29\%) percent than during the day twenty-point five $(20.5 \%)$ percent or at night twenty-five $(25 \%)$ percent. However, the pursuits occurring at dusk only made up a four-point five (4.5\%) percent of the total (Yates, 2009).

\section{Associated Risks}

As common knowledge suggests, there are numerous risks associated with many law enforcement activities. Few of these activities are more dangerous than vehicular pursuits. Therefore, it is important to examine all factors which are more likely to increase the risks of collisions. Overall, risk factors may be difficult to determine because there is currently no data system in the USA which examines the characteristics of LEO collisions other than Fatality Analysis Reporting System (FARS) which deals only with fatalities (Rice, Troszak, \& Gustafson, 2015).

Pursuit-related collisions are inundated with risks to all parties involved, the police, the suspect and the community at large. Overall, pursuits have the potential to result in a predictable number of outcomes. Some of these potential outcomes may 
include the suspect stopping the vehicle voluntarily and surrendering; the pursued vehicle involuntarily colliding with an object and the occupants are injured, killed, apprehended or escape; the pursued vehicle involuntarily collides with a pedestrian with or without causing injury or death; the pursued vehicle involuntarily collides with another vehicle and no injuries occur; the pursued vehicle involuntarily crashes with or without injuries to others; or law enforcement may use force to stop the pursued vehicle. Some uses of force may include firearms, stop-sticks, stingers, roadblocks, moving roadblocks, ramming, bumping, boxing or the pit-maneuver (Alpert \& Anderson, 1986).

There is little debate about the numerous negative outcomes vehicular pursuits present (Morris, 1993). Typically, there are three characteristics of pursuits which are commonly agreed upon regarding pursuits: 1) pursuits are dangerous; 2) pursuits must be regulated and; 3) involvement in pursuits increase the adrenaline and emotional state of the participants (Hess et al., 2014). Some place more emphasis on life and property over the potential to establish a deterrent effect and believe that pursuits should be restricted by law and regulation (Alpert \& Fridell, 1992). A 2015 USA Today article reported that 139 LEOs were killed in high-speed pursuits from 1979 to 2013. During that same period, 5,000 passengers and bystanders and 6,300 suspects were killed because of highspeed chases. Tens of thousands of others sustained personal injury. There is some support for the notion that human and financial costs of pursuits are justified by the need to apprehend suspects and the deterrent effect established through enforcement action (Hannigan, 1992). The financial burden of these pursuits has resulted in plaintiffs receiving monetary awards in the hundreds of thousands and millions of dollars (Zevitz, 1987). 
In addition to the measurable financial tolls resulting from officer-involved vehicle collisions, there are immeasurable emotional tolls placed on families, friends and agencies especially when collisions result in the death of a LEO or private citizen. For collisions that do not result in death, those involved suffer long-term health problems, such as psychological trauma, long-term disabilities and expensive therapies (Wolfe, 2015).

The Physicians for Automotive Safety (PAS) study was one of the first studies to draw attention to the issues surrounding pursuits. They concluded that one in five pursuits ended in death; one in ten pursuits ended in serious injury; and seven of ten pursuits ended in a collision (Fennessy, Hamilton, Joscelyn \& Merritt, 1970). Shortly after the PAS study, the North Carolina Highway Patrol pursuit study was conducted in 1968. The results of this study contradicted the results of the PAS study. Over a oneweek period, troopers were involved in 44 pursuits and only 5 ended with a collision. The collision ratio was 9:1 and the personal injury ratio was 22:1 (Fennessy, Hamilton, Joscelyn, \& Merrit, 1970; Fennessy \& Joscelyn, 1971). Following the Fennessy report, the California Highway Patrol (CHP) conducted a study in 1983. As discussed earlier in this study, they found that three in ten pursuits ended in a collision, one (1\%) percent ended in a fatality and eleven (11\%) percent resulted in personal injury. Each of these studies ended with similar findings. Pursuits have the potential to end with a collision resulting in personal injury or death.

The article Characteristics of Law Enforcement Officer's Fatalities in Motor Vehicle Crashes, was published by NHTSA (2010). It explored demographic and situational factors involved in LEO traffic collisions. This study examined the 
characteristics of collisions occurring between the years 1980 and 2008. NHTSA found that the LEO and non-LEO groups showed substantially different characteristics at most points of examination (2010). However, LEOs typically have more discretion in terms of speeds traveled during pursuits than other emergency vehicles (FEMA, 2014).

In a similar study conducted in Metro-Dade, Alpert and Dunham (1989) found the location of the pursuit to be a significant predictor of collisions and injuries. Additionally, road conditions were found to be a significant predictor of collision and apprehension. It was also concluded that serious injury to either the police or bystanders was rare (Alpert \& Dunham, 1989).

Alpert and Dunham's (1990) study provided some useful context for administrators within policing. In this study, they examined the effect of the officer's age on the pursuit outcome. The study examined several negative outcomes and found that the age of the involved LEOs was the first of seven predictors of collisions. It was determined that pursuits involving LEOs in their twenties $(\mathrm{N}=56)$ and thirties $(\mathrm{N}=42)$ were more likely to result in a collision than LEOs in their forties $(\mathrm{N}=9)$. Conversely, LEOs in their twenties $(\mathrm{N}=41)$ and thirties $(\mathrm{N}=24)$ were less likely to sustain personal injury resulting from the pursuit than LEOs in their forties $(\mathrm{N}=7)$. Overall and conclusively, negative outcomes were higher for LEOs in their twenties ( $\mathrm{N}=83$ or $53 \%)$ and thirties $(\mathrm{N}=59$ or $49 \%)$ than for older LEOs $(\mathrm{N}=7$ or $44 \%)$. Additionally, Alpert and Dunham's (1990) found that older LEOs were more likely to engage in pursuits of longer duration, higher speeds, disregard traffic signals and pursue on freeways. However, older LEOs were less likely to engage in pursuits at night. 
Similarly, Lockie, Dawes, Kornhauser, Holmes, \& Orr (2018) conducted a study to compare the driving characteristics of younger officers and older officers. This evaluation was conducted on a police pursuit driving course (i.e., Driving Program Practical Test (DPPT)) with a sample of 43 incumbent LEOs grouped into two different age groups (i.e., 20-39 and 40-59 years of age). All participates were instructed to complete the driving course as quickly as possible while disturbing the least number of markers possible. A one-way ANOVA was utilized to analyze the results. They found that the 20-39 year group completed the course more quickly but committed more infractions. The 40-59 year group completed the course more slowly but exhibited fewer infractions.

In a comparable study conducted by Rice et al. (2015), found a strong negative association between age and the culpability of a LEO involved in a non-pursuit-related collision. Younger LEOs as compared to LEOs over 50 years of age have higher probabilities of being found culpable in the collisions. From a policy standpoint, it may be useful to monitor and closely supervise the vehicular operations of younger LEOs more closely. The early identification of LEOs who lack proficient skill in vehicle operation is also important. Additional driver training, pursuit training and risk inoculation for younger LEOs could lead to reduced collision involvement.

When assessing the costs and benefits of engaging in pursuits, some argue that arrests stemming from pursuits may lead to marginal results under the deterrence and incapacitation theory (Chamlin, 1988; Greenberg \& Kessler, 1982; Greenberg, Kessler, \& Logan, 1979). However, others state that there is no data available which directly leads 
to a crime reduction or deterrent effect resulting from any arrests made after the pursuit (Crew \& Hart, 1999).

An empirical analysis was conducted by Crew, Kessler, \& Fridell, (1995) which examined the costs and benefits involved in pursuits. They found that the costs and benefits tended to vary in relation to the events that initiated the pursuit. This study supported the notion that costs of pursuing were relatively high in relation to any potential benefits gained from engaging in the pursuit for a specific violation.

Crew and Hart (1999) conducted a study in Minnesota to assess the value gained from engaging in vehicular pursuits and built upon the earlier works of Crew et al. (1995). To operationalize this study, they had to attach a monetary value to any arrest made at the end of a pursuit. This was done by assigning the value that "one pays for a crime" as the average monetary cost of a crime. They operationalize the cost of a pursuit in two ways: 1) the average amount paid in claim costs for bodily injury and property damage as reported by the American Insurance Industry (Insurance Information Institute, 1997); and 2) the average financial value of a fatality as assessed by Miller (1990). This logic was consistent with the methodology utilized in civil law damage suits by which the guilty party is assessed a monetary award for any damages, injuries and deaths resulting from their actions (Crew \& Hart, 1999). At the time this study was conducted, the estimated damages sustained in Minnesota was $\$ 185$ million worth of accidents, injuries and deaths which were a result of pursuits. The total value, however, of the benefits to Minnesota were found to outweigh the costs 60 -fold to the amount of $\$ 11$ billion. Crew and Hart (1999) also found that pursuits were nearly 30 percent more likely to end in a negative outcome. Further, certain types of pursuits were more likely to result in a 
negative outcome which was dependent upon the incident that precipitated the pursuit (Crew and Hart, 1999).

Vila (2000, 2006) identified the officer's level of fatigue as a contributing factor in LEO collisions. The author stated that LEO's fatigue may lead to errors in judgement which may result in collisions. Some argue that driving while fatigued is like driving while intoxicated (Williamson, Feyer, Mattick, Friswell, \& Finlay-Brown, 2001). A person who has been awake for 20 hours possesses a similar diminished capacity to operate a motor vehicle as someone who is legally drunk with a blood-alcohol content of 0.08 (Dawson \& Reid, 1997). It is commonly accepted that fatigue may result in dangerous situations in many aspects. Yet no standard exists to regulate LEOs from being overly fatigued while working. Vila (2000, 2006, and 2009) argues further that the shift work experienced by LEOs may have a lasting and compounding effect on work output and levels of fatigue. Many LEOs may not be adequately rested and prepared to make sound judgements on the job (Vila \& Gustafson, 2011, p. 12).

James and Vila (2012) also studied LEOs involved in collisions as they relate to distraction. Prior to the many technological innovations of recent times, patrol vehicles were just that, patrol vehicles. LEOs were used to drive in and around a designated area at slow speeds while on patrol. Today, a great many items create unintended distraction for the LEO. Some of these things include mobile data terminals, video cameras, in-car radios and cellular phones. Bener, Lajunen, Özkan, and Haigney, (2006) specifically researched cellular telephone usage in the general population and determined that the distraction created resulted in statistically significant increases in collision rates. Some states began to enact "hands free" laws to counteract this commonly accepted belief. 
Abdel-Aty (2003) found that drivers were distracted when using a cellular phone-hands free or otherwise. This finding was also substantiated by McCartt, Hellinga, \& Bratiman (2006) who conducted a meta-analysis of 125 studies.

Today, for the LEO, mastering the art of being able to rapidly divert attention to multiple tasks is paramount and, in some cases, can be the difference between life and death. Some believe that human beings can only focus attention on one thing at a time and that multitasking is a myth. Some people may become very adept at switching from one task to another and then refocusing, but this is not multitasking or focusing on multiple tasks at the same time (James \& Vila, 2012; Loukopoulos, Dismukes, \& Barshi, 2009; Rosen, 2008). When LEOs are confronted with multiple tasks requiring immediate attention during situations such as a pursuit, the LEOs mind must shift focus from one thing to another continually in rapid succession. This pattern of shifting focus diminishes cognitive resources throughout the incident and over time during work shift. This occurs regardless of whether the LEO does so actively and consciously. The mere presence and persistence of these multiple tasks can adversely affect work performance over time (James \& Vila, 2012).

Many academics view LEO collisions and fatalities as being caused by a lack of command-and-control management or agency policy (Batiste, Wagers, \& Ashton, 2011; Gustafson, 2009; IACP, 2011; Schultz, Hudak, \& Alpert 2009). The common theme among those that have studied this aspect is that law enforcement administrators should set expectations in policy and in practice which hold LEOs accountable for driving responsibly. With speed and failure to wear seatbelts being a factor in approximately half of the fatalities and traffic collisions, it can be argued that some of these accidents are 
preventable. Schulz et al., (2009) conducted research on traffic collisions and fatalities resulting from pursuits. They found that permissive pursuit policies were linked to higher collision rates and fatalities.

Some have linked aggressive driving and risk-taking behaviors as correlates to collision involvement (Castro, 2008; Dorn, 2005, 2010). These authors suggest that individual factors (i.e., personality/behavioral/cognitive) can contribute to a higher likelihood of collisions. Training, screening, and pursuit monitoring have been suggested as remedies (Castro, 2008; Dorn and Barker, 2005; Dorn, 2010).

LaTourrette (2015) conducted a study which examined the environmental, vehicle or individual-level characteristics associated with LEO collisions and of these characteristics, which possesses the greatest risk collision-related injury. A crosssectional survey was distributed to a national sample of law enforcement agencies to collect information about LEO collisions. This national sample was separated into 12 groups composed of a municipal, county, and state police agencies. These agencies were then separated into four geographic regions as defined by the US Census Bureau. The survey instrument contained questions about collision causal factors, vehicle information and operator information. This study did not examine different driving conditions or driver characteristics. LaTourrette (2015) found that 80 percent of non-minor crashes occurred without lights or sirens activated. However, LEOs had three to four times a greater risk of injury with lights or sirens activated. LEOs were twice as likely to sustain an injury with lights only activated. Seventy percent of the injuries occurred during routine, non-emergency driving situations. Some risk factors for collisions with more substantial injuries include failure to wear seatbelts, vehicle type (i.e., motorcycle riders). 
Risk of injury was twice as probable in collisions occurring during the day as compared to the night. Lastly, LaTourrette (2015) found a marginally significant relationship between pursuit training and collisions with lights and sirens activated. Remarkably, LaTourrette (2015) did not find significantly elevated risk of injury in operator distractions, operator age and work experience, and operator amounts of sleep and operator work history.

Once the decision is made that a pursuit must be terminated because the danger presented is too great, an intervention technique must be selected and employed to end the pursuit. Most intervention strategies also pose a risk of collision. Various pursuit intervention techniques present considerably less risk than others. Some of these techniques include the use of tire deflation devices to safely stop the suspect vehicle, aerial surveillance to safely track the suspect vehicle, and GPS tracker technology used to observe the suspect vehicle until it voluntarily stops. Other pursuit intervention techniques which are somewhat less safe involve the use of the patrol vehicle to "box in" or "channel" the suspect vehicle to a safer location suitable for apprehension. The riskiest techniques involve vehicle to vehicle contact through what is called legal intervention. A more comprehensive discussion of these risk management strategies is presented within policy recommendations because it is unclear what are the trends and correlates of collisions and injuries in the Kentucky State Police.

Pursuits, typically, involve the police, the suspect and often innocent by-standers in the public (Dunham, 1998). Police are constrained by agency policy, training and supervision. Conversely, suspects are not constrained by any factors making it nearly 
impossible to regulate their behavior without their voluntary compliance (Dunham, 1998).

LEOs spend much of their time operating a motor vehicle. The time they spend in a vehicle is, substantially, more than the time an average citizen spends driving. Additionally, LEOs engage in many activities that may be considered violations of the law by private citizens such as pursuit driving, high speed emergency response driving and violation of roadway laws (Wolfe et al., 2015). Even so, pursuits remain one of the most dangerous activities LEOs engage in on the job. Over the last two decades, the leading cause of death for LEOs is traffic collisions (FBI, 2008B; National Law Enforcement Officers Memorial Fund, 2014; NLEOMF, 2009; President Obama's Task Force on $21^{\text {st }}$ Century Policing, 2015). It has been so prevalent that the federal government (FBI, 2008b; NHTSA, 2010b) has identified it as a primary occupational hazard for LEOs (NIOSH, 2009).

One of the goals law enforcement agencies have in the interest of mitigating risk is to remove split-second decisions from the LEO involved in the pursuit who is under extreme amounts of stress and adrenaline (Alpert, 1998). This may be accomplished by supervisory staff monitoring the pursuit over the mobile radio as the pursuing LEO relays moment by moment accounts to radio dispatch. This allows for a neutral and detached supervisor to make real-time decisions about the pursuit based upon the reason for the pursuit, the location, speed and any number of risk factors present at the time. LEOs engaged in pursuits also evaluate the same factors. Then individually or collectively LEOs and supervision decide to continue the pursuit or terminate the pursuit pending further action. 
If it is decided that a pursuit should or must be terminated, many LEOs cite the following reasons for terminating a pursuit: traffic conditions, certain speed zones and dangerous conditions (Falcone, 1994). Britz and Payne (1994) showed there was a difference in attitude relating to pursuits between line level LEOs and administrators. In this study, LEOs reported serious deficiencies in written pursuit policy and issues with pursuit training. Thirty-eight (38\%) percent of respondents viewed their agency's pursuit policy difficult to comprehend and implement. Homant and Kennedy (1994) reviewed a study to assess risk and pursuit tendencies among line LEOs from departments with different policies. As expected, they found that LEOs with permissive policies were more inclined to engage in pursuits while LEOs with more restrictive policies pursued less often (Homant \& Kennedy, 1994). Alpert and Madden (1994) focused on police supervisors, recruits and criminal justice students. They estimated the impact of four critical factors on a LEO's decision to pursue a suspect. These four factors included 1) type of offense committed; 2) location of the pursuit; 3) perceived need to apprehend the suspect and 4) traffic and weather conditions. Supervisors reported the perceived need to apprehend was more important than the risk posed to the LEO and department. They also found that the enforcement of certain laws received priority over the safety of the public. Students however, reported the perceived risk factors as more important than the perceived need to apprehend. Overall, Alpert and Madden (1994) found that the most important factor influencing a LEO's decision to pursue a suspect among all groups of respondents was the need to apprehend the suspect. Traffic conditions were determined to be second most important factor followed by the location of the pursuit and weather conditions which ranked last. 
Another study conducted by Alpert (1998) utilized the same three levels of respondents (i.e., students, police recruits and police supervisors) as Alpert and Madden (1994) to examine factors influencing the decision to pursue including location. This study showed that in some cases, the LEOs' attitudes conflicted with agency policy. LEOs and supervisors responded that the "area of pursuit" had no significant effect on engaging in a vehicular pursuit whether in a commercial area or on a freeway. Pursuits, however, were less likely to occur in inner-cities or residential environments. LEOs and supervisors both reported that the most important factor in the decision to pursue was the need to apprehend. Traffic conditions were determined to be the most important risk factors.

As discussed, there are numerous negative outcomes associated with vehicular pursuits. The findings from numerous studies have been presented. Understandably, law enforcement agencies have an obligation to thoroughly investigate pursuits and employ effective risk management strategies as a means of mitigating negative outcomes. For a risk to be mitigated, it is necessary to have a clear understanding of factors contributing to the risk associated with collisions and injuries.

To reduce risk and improve safety for those involved in pursuits as well as all others, it is important to have a perspective on the leading contributing factors of these collisions and injuries. This type of information relating to these causes may be more accurate and easily obtained from the LEOs involved in these collisions due to the thorough investigations, which typically occur after any collision involving a police cruiser. The focus of this study will be centered on this type of data as addressed in the literature and collected in the KSP data set. 


\section{$\underline{\text { Research Questions }}$}

This study will utilize two research questions. The first research question pertains to the trend analysis. The first research question is: what are the trends in collisions and injuries within Kentucky State Police vehicular pursuit practices? The second research question is: what are the correlates of collisions and injuries within Kentucky State Police vehicular pursuit practices? 


\section{CHAPTER 3}

\section{METHODOLOGY}

This study examines the relationship between pursuit-related collisions and injuries over time through a trend analysis. Collisions and injuries were also examined in relation to numerous potential contributing factors contained within the data set.

The data used for this study was obtained from the Strategic Planning Branch (SPB) of the KSP. The SPB obtained and compiled this pursuit data by reviewing state police Teletype reports which, per policy, are created for each pursuit. Each pursuit Teletype report (pursuit Teletype) is completed in the Computer-Aided Dispatch (CAD) system by KSP dispatchers working at each respective post. Pursuit Teletypes are required to be completed after every pursuit involving KSP personnel. The CAD Teletype template contains the following fields to ensure standardization of the data collected: 1) when did the pursuit occur?;2) which post area did the pursuit occur in?;3) which agency initiated the pursuit?; 4) how many police units were involved in the pursuit?; 5) was the suspect apprehended after the pursuit?; 6) did the suspect resist arrest after the pursuit?; 7) did the suspect flee after being stopped by the police?; 8) did a fatality occur as a result of the pursuit?; 9) did the suspect flee on foot once stopped?; 10) was a tire deflation technique used to stop the suspect?; 11) was a legal intervention technique used to stop the suspect?; 12) was the rolling road block technique used to stop the suspect; 13) did any injuries occur as a result of the collision; 14) did a collision occur as a result of the pursuit?; 15) what was the distance the pursuit traveled?; 16) what was 
the duration of the pursuit?; 17) what was the top speed of the pursuit?; 18) what was the vehicle type driven by the suspect pursued?; 19) was the pursuit terminated by law enforcement?; 20) if terminated, why was the pursuit terminated by law enforcement?; 21) was the pursued suspect a juvenile?; 22) what was the violation for which the pursuit was initiated?

Then periodically, the SPB consolidates the pursuit data collected on the Teletypes in to an excel spreadsheet for each respective calendar year. The author obtained these spreadsheets and combined them into one spreadsheet containing calendar years 2009 through 2017. Once reformatted, recoded and checked for errors, this spreadsheet was imported into SPSS 22 and Stata 15 to create and analyze the data set in this study. The author also created a codebook to accompany this data set.

\section{$\underline{\text { Measures }}$}

Based upon the literature, several measures were identified and will be used in this study. The dependent measures are pursuit-related collisions and injuries. In research, the dependent variable $(Y)$ is impacted by the independent variable(s) $(X)$ to produce an effect (Vito \& Blankenship, 2002). The pursuit-related collisions and injuries dichotomous variables will be used as the dependent variables. They were coded $($ No Collision $=0$, Collision $=1)$ and $($ No Injury $=0$, Injury $=1)$ respectively .

In research, independent variables produce an effect or impact the dependent variable (Vito \& Blankenship, 2002). Other measures included in the dataset will be examined as correlates to pursuit-related collisions and injuries depending on their variance in the data. Rice, Troszak and Gustafson (2015) note inexperienced drivers (i.e., 
juveniles) as a risk factor in collisions. However, only $2 \%$ of the suspects were minors. Similarly, although there are 47 violations which resulted in pursuits being initiated by the KSP, only those that are more frequent will be considered here. As noted in the literature, traffic violations were the most often cited reason for initiating pursuits. Of those violations, the following violations were more common and will be used as independent measures (Speeding 31\%; Reckless Driving 12\%; Avoiding/Fleeing Traffic Checkpoints 5\%; No/Expired Registration Plates 5\%; and Driving under the Influence $4 \%)$. Individual characteristics of the officer and suspect and environmental characteristics were not available within the data therefore were not utilized in this study.

Independent measures selected for analysis are 1) Number of Units Involved; 2) Tire Deflation Used; 3) Rolling Road Block Used; 4) Distance of the Pursuit; 5) Duration of the Pursuit; 6) Top Speed of the Pursuit; 7) Juvenile Suspect; 8 - 12) Violation Causing the Pursuit. They were coded as follows: 1) Number of Units Involved (1-2 Units $=0 ; 3$ or more Units $=1$ ); 2) Tire Deflation Used (No Tire Deflation Used = 0, Tire Deflation Used = 1); 3) Rolling Road Block (No Rolling Road Block Used = 0; Rolling Road Block Used = 1); 4) Distance of the Pursuit (5 Mile or less = 0; 6 Miles or farther =1) 5) Duration of the Pursuit (5 Minutes or fewer $=0$; 6 Minutes or longer $=1$ ); 6) Top Speed of the Pursuit (65 MPH or Less $=0$; $66 \mathrm{MPH}$ or More $=1)$; 7) Juvenile suspect (Adult = 0; Juvenile $=1) ; 8-12)$ Violation Causing the Pursuit $($ Other $=0$; Speeding $=1)$; (Other $=0 ;$ Reckless Driving = $) ;($ Other $=0 ;$ No/Expired Registration Plates $=1) ;($ Other $=0$; Avoiding/Fleeing Traffic Checkpoint $=1)$; and $($ Other $=0$; Driving under the Influence $=$ $1)$. 


\section{$\underline{\text { Analysis Plan }}$}

Overall, three major steps will be taken to provide information that will address the research questions. The first step is a presentation of the descriptive statistics that will provide clear information about the distribution of the data. Descriptive statistics are a way of summarizing the data by presenting information such as the count or how the data is distributed (Vito \& Blankenship, 2002). The descriptive statistics that will be used in this study include the following: mean, standard deviation, minimum and maximum.

The second major step in the analysis is the trend analysis. To be clear, the trend analysis will address the following research question: what are the trends in collisions and injuries in the Kentucky State Police vehicular pursuit practices? To address this research question, the trend analysis will be performed following the guidelines from the Center for Disease Control and Prevention (CDC). The CDC advocates a multi-step process for examining trends.

The first step (Step 1) of the trend analysis is a series of regression analyses. Given the dependent measure for this study is dichotomous, the regression of choice is logistic regression. In other words, three logistic regression analyses will be performed to determine the shape of the trends of collisions. Each logistic regression will include an orthogonal polynomial version of year. This is done to determine whether the change in 
collisions is linear, quadratic, or cubic per the CDC guidelines. The highest polynomial that is statistically significant will be used for further analysis. ${ }^{1}$

The second step (Step 2) of the trend analysis, if the change in collisions is quadratic or cubic, is to determine in what years the greatest and statistically significant changes occur. To perform this analysis, the margins from the logistic regression that contains the largest polynomial will be entered in the National Cancer Institute's Joinpoint program. The Joinpoint program uses the Bayesian analysis to determine the proper location of where the largest change took place resulting in a number of segments. If the analysis is examining a quadratic change, two segments would be found. If the analysis is examining a cubic change, three segments would be found.

The third step (Step 3) of the trend analysis is an analysis of whether the segments from a quadratic or cubic analysis are linear and the average percent change for each segment. This will require more logistic regression analyses. Each logistic regression would include a linear polynomial. If the linear polynomial is significant, then the segment is viewed as linear. In addition, for each segment, an additional logistic regression will be executed that will provide information about the average percent change for each segment.

These three steps will provide valuable information to address the first research question. Results of this type do not appear in the research literature nor do they appear

\footnotetext{
${ }^{1}$ As a side note, a linear polynomial is smallest polynomial tested in this analysis. A quadratic polynomial is larger than a linear polynomial, but it is smaller than a cubic polynomial. Further, the cubic polynomial is considered the largest of all three polynomials that are being examined.
} 
in any report by the Kentucky State Police. The trend analysis, thus, may provide unique information in the context of pursuit collisions.

The third major step in the analysis is an examination of the correlates to a collision using logistic regression analysis. Specifically, after the trend analysis, the second research question will be addressed. The second research question is: what are the correlates of a collision in the Kentucky State Police vehicular pursuit practices? As with the trend analysis, logistic regression analysis was used because the dependent measure was dichotomous (Pallant, 2013). 


\section{CHAPTER 4}

\section{RESULTS}

\section{$\underline{\text { STEP } 1 \text { - Descriptive Statistics }}$}

The KSP Pursuit dataset created for this study contained a population size of ( $N=1200)$ pursuits. This entire population (i.e., 2009-2017) was used in this study. Regarding the dependent variables, there were a total of $(31 \%, \mathrm{~N}=355)$ collisions and (18\%, N=170) injuries occurring during this period (TABLE 1). Regarding injuries, only $(1 \%, N=9)$ of the pursuit resulted in fatality of the suspect. The majority of the injuries were to the suspect $(9 \%, \mathrm{~N}=94)$ with $(6 \%, \mathrm{~N}=63)$ to the officer, $(0.3 \%, \mathrm{~N}=3)$ to the public and $(0.2 \%, \mathrm{~N}=2)$ to the passenger. 


\section{TABLE 1}

Descriptive Statistics

\begin{tabular}{llllll}
\hline Measure & Mean & SD & Minimum & Maximum & Sum
\end{tabular}

\section{Dependent Variable}

$\begin{array}{llllll}\text { Collisions } & 0.31 & ----- & 0 & 1 & 355 \\ \text { Injuries } & 0.18 & ----- & 0 & 1 & 170\end{array}$

\section{Independent Variables}

\begin{tabular}{lrllll} 
Post Location & 7.22 & 5.013 & 1 & 16 & 8637 \\
Month & 6.47 & 3.367 & 1 & 12 & 7,759 \\
Units & 2.42 & 2.582 & 1 & 20 & 2,902 \\
Units & 0.27 & ------ & 0 & 1 & 320 \\
Tire Deflation & 0.13 & ------ & 0 & 1 & 154 \\
Rolling Road & 0.04 & ----- & 0 & 1 & 16 \\
Distance & 10.68 & 12.404 & 0 & 105 & 12,239 \\
Distance & 0.52 & ------ & 0 & 1 & 594 \\
Duration & 10.15 & 11.294 & 1 & 140 & 10119 \\
Duration & 0.56 & ----- & 0 & 1 & 556 \\
Topspeed & 85.76 & 27.215 & 0 & 175 & 101,366 \\
Topspeed & 0.74 & ------ & 0 & 1 & 879 \\
Juvenile & 0.02 & ------ & 0 & 1 & 20 \\
Speeding & 0.31 & ------ & 0 & 1 & 367 \\
Reckless & 0.12 & ------ & 0 & 1 & 144 \\
Checkpoint & 0.05 & ------ & 0 & 1 & 64 \\
Reg. Plates & 0.06 & ------ & 0 & 1 & 70 \\
DUI & 0.04 & ------ & 0 & 1 & 51 \\
& & & & & \\
\hline
\end{tabular}

Numerous independent variables were examined in this study. Most of the pursuits, collisions and injuries occurred during the month of April and during the year 2017. Pursuits occurred throughout Kentucky with most of the pursuits taking place in the Post 11 London $(\mathrm{N}=125)$ area. The fewest pursuits occurred in the Post 7 Richmond Area (N=36). Most pursuits only involved one LEO which was consistent with the literature (Alpert, 1997). There was a total of 2,606 LEOs involved in all the pursuits for a mean of 2.42 units per pursuit. Twenty-six-point seven $(26.7 \%)$ percent of pursuits 
involved three or more units. Tire deflation devices were used during 154 of the pursuits while rolling roadblocks were used only 16 times. Most often, pursuits were 2 miles in distance while the average distance was 10.68 miles overall. Most pursuits were 6 miles or farther covering a total of 12,239 miles overall. Most pursuits were 2 minutes in duration while the mean duration was 10.15 minutes long. The majority of pursuits were 6 minutes or longer and the time covered for all pursuit encompassed 10,119 minutes or 168 hours and 39 minutes. The distance and duration are also consistent with the literature which found most pursuits to be shorter in distance (Yates, 2009) and shorter duration (Beckman, 1983; Payne and Fenske, 1997). The top speed was 66 miles per hour or more approximately $74 \%$ of the time. A juvenile suspect was only involved in 20 of the 1,200 pursuits. As indicated in the literature and confirmed in the KSP pursuit data (72.3\%), the most common violation for which a pursuit was initiated was a traffic violation (Alpert \& Dunham, 1990; Alpert and Fridell, 1992; Auten, 1991; Beckman, 1983; Charles, Falcone \& Wells, 1992; Payne \& Fenske, 1997). Of these traffic violations, speeding $(31 \%, \mathrm{~N}=367)$, reckless driving $(12 \%, \mathrm{~N}=144)$, fleeing a traffic safety checkpoint $(5 \%, \mathrm{~N}=64)$, no/expired registration plates $(6 \%, \mathrm{~N}=70)$ and driving under the influence (4\%, $\mathrm{N}=51)$ were the most prevalent violations (TABLE 1).

Other statistics of interest regarding KSP pursuits are as follows. A total of 900 suspects $(75 \%$ of the 1,200$)$ pursued were apprehended. Pursuits were infrequently subject to termination $(20 \%, \mathrm{~N}=243)$. The leading two reasons pursuits were terminated were: when the officer lost sight of the suspect $(9 \%, \mathrm{~N}=114)$ and when the pursuit entered a restricted zone/area $(2 \%, \mathrm{~N}=32)$. Logistic regression will be the primary means of 
analysis which does not require a normal distribution of data. Therefore, it is unnecessary to report skewness and kurtosis.

\section{$\underline{\text { STEP } 2 \text { - Trend Analysis }}$}

Trend analysis was utilized to answer the first research question which is "What are the trends in collisions and injuries in the Kentucky State Police vehicular pursuit practices?" A series of three logistic regressions were run for each dependent variable. Three variations (i.e., linear, quadratic and cubic) of the time frame year were utilized in step one of the trend analysis process. It was determined that only the linear models were found to be significant for both the dependent variables (i.e., collisions and injuries). This was somewhat surprising regarding injuries because there was a spike in 2014 $(\mathrm{N}=36)$ followed by a sharp decrease in $2015(\mathrm{~N}=21)$ which could have resulted in a quadratic trend, but the data did not show this occurring. Because the quadratic $(p=.16$ and $\mathrm{p}=.41)$ and cubic $(\mathrm{p}=.69$ and $\mathrm{p}=.68)$ logistic regression models were not found to be significant, Steps 2 and 3 of the trend analysis were unnecessary and Joinpoint software was not utilized to determine the critical values. However, the linear trends may be interpreted for both dependent variables.

Across all years (i.e., 2009 - 2017), 31\% percent of pursuits ended in a collision and $18 \%$ of pursuits ended in injury. As illustrated in TABLE 2 and TABLE 3, the analysis concluded with evidence of increasing trends in collisions $(b=0.17)$ and injuries $(b=0.18)$ across time. Collisions occurred at a rate of $22 \%$ in 2009 . This rate gradually increased to an all-time high of $32 \%$ in 2017. Similarly, the injuries rate in 2009 was 13\%. The injury rate increased steadily to $20 \%$ in 2017. 
TABLE 2

$\underline{\text { Trends in Pursuit-related Collisions }}$

\begin{tabular}{lllrl}
\hline Year & Prevalence & Polynomials & Beta & P-value \\
All Years & 0.31 & Linear & 0.17 & 0.05 \\
2009 & 0.22 & & & \\
2010 & 0.23 & Linear & -5.41 & 0.16 \\
2011 & 0.24 & Quadratic & 2.21 & 0.16 \\
2012 & 0.25 & & & \\
2013 & 0.27 & Linear & -5.41 & 0.16 \\
2014 & 0.28 & Quadratic & 2.21 & 0.16 \\
2015 & 0.29 & Cubic & 0.00 & 0.69 \\
2016 & 0.30 & & & \\
2017 & 0.32 & & & \\
\hline
\end{tabular}

TABLE 3

$\underline{\text { Trends in Pursuit-related Injuries }}$

\begin{tabular}{lllrl}
\hline Year & Prevalence & Polynomials & Beta & P-value \\
All Years & 0.18 & Linear & 0.18 & 0.05 \\
2009 & 0.13 & & & \\
2010 & 0.14 & Linear & -4.30 & 0.43 \\
2011 & 0.14 & Quadratic & 1.77 & 0.41 \\
2012 & 0.15 & & & \\
2013 & 0.16 & Linear & ------ & ----- \\
2014 & 0.17 & Quadratic & ----- & ----- \\
2015 & 0.18 & Cubic & 0.00 & 0.68 \\
2016 & 0.19 & & & \\
2017 & 0.20 & & & \\
\hline
\end{tabular}

Overall, the number of pursuit-related collisions and pursuit-related injuries has increased from 2009 to 2017 for the KSP (FIGURE 1). 


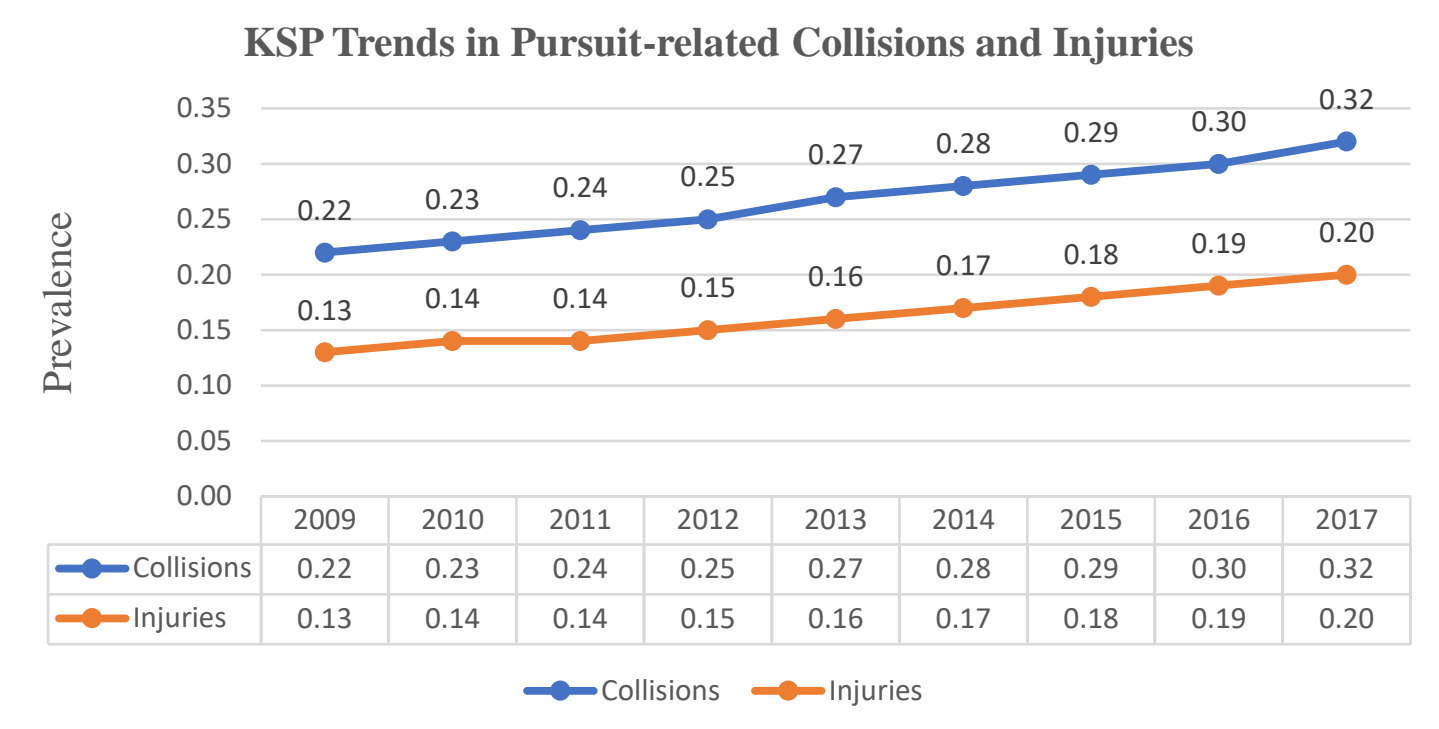

Figure 1. KSP Trends in Pursuit-related Collisions and Injuries. This figure illustrates the trends in KSP pursuit-related collisions and injuries between 2009 and 2017.

\section{$\underline{\text { STEP } 3 \text { - Logistic Regressions }}$}

Logistic regression was utilized to address research question number two, "What are the correlates of collisions and injuries in the Kentucky State Police?" Two logistic regressions were utilized to determine if any of the independent variables identified in the literature can provide some predictive value in the dependent variables. The independent variables utilized in these logistic regressions were 1) Year; 2) Number of Units Involved; 3) Tire Deflation Used; 4) Rolling Road Block Used; 5) Distance of the Pursuit; 6) Duration of the Pursuit; 7) Top Speed of the Pursuit; 8) Juvenile Suspect; 9 13) Violation Causing the Pursuit (i.e., Speeding, Reckless Driving, No/Expired Registration Plates, Avoiding/Fleeing Traffic Checkpoint, Driving Under the Influence). Logistic regression was chosen as the method of evaluation because the dependent variables were dichotomous. A logistic regression was also conducted between the two dependent variables which indicated statistical significance at $\mathrm{p}=0.000$. 
Two models were developed, one for collisions (Model 1) and one for injuries (Model 2). Each model was tested for collinearity and contain thirteen independent measures. For Model 1 (TABLE 4), two of the independent variables were found to be statistically significant and provided predictive value in determining collisions. Those variables were "Tire Deflation Used" ( $p=0.024$; S.E. $=0.144$; Odd Ratio=0.436) and "Number of Units Involved" ( $\mathrm{p}=0.033$; S.E. $=0.057$; Odd Ratio=1.126). This indicates that whenever a tire deflation device was used, the potential for collisions decreased by fifty-six point four $(56.4 \%)$ percent. Conversely, whenever three or more units were involved in a pursuit, the pursuit was 1.126 times more likely to end in a collision.

\section{TABLE 4}

$\underline{\text { Model } 1 \text { - Logistic Regression - Pursuit-Related Collisions }}$

\begin{tabular}{|c|c|c|c|c|c|c|}
\hline \multirow[t]{2}{*}{ Measure } & \multirow[t]{2}{*}{ Odds Ratio } & \multirow[t]{2}{*}{ S.E. } & \multirow[t]{2}{*}{$\mathbf{t}$} & \multirow[t]{2}{*}{$\mathbf{p}$} & \multicolumn{2}{|c|}{ 95\% C.I. Odds Ratio } \\
\hline & & & & & Lower & Upper \\
\hline \multicolumn{7}{|l|}{ Independent } \\
\hline \multicolumn{7}{|l|}{ Variables } \\
\hline Year & 1.170 & 0.198 & 0.93 & 0.368 & 0.816 & 1.676 \\
\hline Units & 1.126 & 0.057 & 2.33 & 0.033* & 1.010 & 1.254 \\
\hline Tire Deflation & 0.436 & 0.144 & -2.50 & $0.024 *$ & 0.216 & 0.881 \\
\hline Rolling Road & 2.189 & 1.701 & 1.01 & 0.328 & 0.421 & 11.369 \\
\hline Distance & 0.611 & 0.292 & -1.03 & 0.319 & 0.222 & 1.684 \\
\hline Duration & 1.784 & 0.880 & 1.17 & 0.258 & 0.626 & 5.079 \\
\hline Topspeed & 0.885 & 0.252 & -0.43 & 0.676 & 0.484 & 1.620 \\
\hline Juvenile & 1.832 & 1.278 & 1.87 & 0.398 & 0.417 & 8.044 \\
\hline Speeding & 0.937 & 0.296 & -0.20 & 0.841 & 0.479 & 1.833 \\
\hline Reckless & 0.488 & 0.171 & -2.05 & 0.058 & 0.232 & 2.026 \\
\hline Checkpoint & 0.251 & 0.271 & -1.28 & 0.220 & 0.025 & 2.493 \\
\hline Reg. Plates & 1.499 & 0.873 & 0.69 & 0.497 & 0.435 & 5.156 \\
\hline DUI & 0.731 & 0.352 & -0.65 & 0.526 & 0.263 & 2.031 \\
\hline
\end{tabular}

$* p<0.05$

For Model 2 (TABLE 5), none of the independent variables provided any predictive value in determining injuries. 
TABLE 5

$\underline{\text { Model } 2 \text { - Logistic Regression - Pursuit-Related Injuries }}$

\begin{tabular}{|c|c|c|c|c|c|c|}
\hline \multirow[t]{2}{*}{ Measure } & \multirow[t]{2}{*}{ Odds Ratio } & \multirow[t]{2}{*}{ S.E. } & \multirow[t]{2}{*}{$\mathbf{t}$} & \multirow[t]{2}{*}{$\mathbf{p}$} & \multicolumn{2}{|c|}{ 95\% C.I. Odds Ratio } \\
\hline & & & & & Lower & Upper \\
\hline \multicolumn{7}{|l|}{ Independent } \\
\hline Year & 1.068 & 0.168 & 0.42 & 0.680 & 0.764 & 1.494 \\
\hline Units & 1.043 & 0.060 & 0.74 & 0.471 & 0.922 & 1.180 \\
\hline Tire Deflation & 0.788 & 0.400 & -0.47 & 0.646 & 0.268 & 2.314 \\
\hline Rolling Road & 1.604 & 1.350 & 0.56 & 0.582 & 0.269 & 9.554 \\
\hline Distance & 0.590 & 0.279 & -1.11 & 0.282 & 0.217 & 1.608 \\
\hline Duration & 1.566 & 0.479 & 1.47 & 0.162 & 0.819 & 2.996 \\
\hline Topspeed & 1.473 & 0.820 & 0.70 & 0.497 & 0.452 & 4.799 \\
\hline Juvenile & 3.791 & 3.371 & 1.62 & 0.124 & 0.656 & 24.021 \\
\hline Speeding & 1.054 & 0.311 & 0.18 & 0.859 & 0.563 & 1.974 \\
\hline Reckless & 0.459 & 0.340 & -1.05 & 0.310 & 0.095 & 2.214 \\
\hline Checkpoint & 1.042 & 0.691 & 0.06 & 0.951 & 0.255 & 4.253 \\
\hline Reg. Plates & 1.441 & 0.573 & 0.92 & 0.372 & 0.620 & 3.342 \\
\hline DUI & 1.383 & 0.708 & 0.63 & 0.535 & 0.467 & 4.096 \\
\hline
\end{tabular}

$* p<0.05$ 


\section{CHAPTER 5}

\section{DISCUSSION}

This study sought to examine the trends involving KSP pursuit-related collisions and injuries over a span of years (STEP 2). It also sought to determine if some of the contributing factors (i.e., measures) identified in the literature can serve as predictors to collision and injuries (STEP 3).

\section{$\underline{\text { Trends }}$}

Regarding the trend analysis utilized to answer the first research question, it was determined that there is an increasing linear trend present with pursuit-related collisions and injuries for this time frame. The rates of collision trended upward from 2009 through 2017. Similarly, the trends for injuries also increased. This was reasonable based upon the significant $(\mathrm{p}<0.001)$ relationship between collisions and injuries.

\section{$\underline{\text { Predictors }}$}

The secondary research question was addressed with logistic regressions. As the literature suggests, there are certain factors which may increase the likelihood of negative outcomes. These measures include having three or more police units participating in the pursuit, deploying a tire deflation device against the suspect vehicle, using a rolling road block involving multiple units to slow or stop the suspect vehicle, engaging in pursuits that extend farther than 5 miles, engaging in pursuits that last longer than 5 minutes, 
participating in pursuits which reached speeds in excess of 65 miles per hour, pursuits involving inexperienced operators such as juvenile suspects, and pursuits which were originally initiated for the violation of speeding, reckless driving, avoiding or fleeing a traffic safety checkpoint, no or expired registration plates or suspicion of driving under the influence.

The results of the logistic regressions concluded that two measures were determined to have some predictive value in determining whether collisions occur. The first involves pursuits with three or more police units participating in the pursuit. The results indicate that this increases the likelihood for collisions to occur. This is reasonable because when more than one police unit is placed in proximity to the suspect vehicle, it increases the likelihood of collisions (Alpert, 1997). Conversely, the risk of collision decreases when a LEO deploys a tire deflation device against the suspect's vehicle. The results suggest that this intervention technique decreases the chance for collision. This is also sensible. Once a suspect vehicle travels over a tire deflation device (i.e., Stingers or Stop Sticks) they begin to lose air pressure in their tires. This typically occurs without causing a blowout or sudden loss of control and usually results in an immediate decrease in speed (Federal Signal, 2017; Stop Stick, 2019). This can decrease the potential for collision and substantially increase safety for all those involved. Additionally, pursuits that were initiated for reckless driving by the suspect present some potential for predicting collisions. Surprisingly, none of the measures identified were useful in predicting injuries.

The factors identified as statistically significant predictors of collisions for the KSP may be generalizable across law enforcement agencies. Especially, agencies of 
comparable size, structure, and pursuit practices. Further, based upon the literature some if not all the factors identified in other studies may present the potential for pursuitrelated negative outcomes for law enforcement agencies. The policy recommendations section provides a comprehensive overview of potential remedies to the predictors identified in this study and some pertaining to the contributing factors as identified in the literature.

\section{POLICY RECOMMENDATIONS}

This section builds upon the findings of this study and the literature reviewed regarding pursuit-related collisions to provide policy recommendations. These recommendations may be generalizable across many types of law enforcement agencies and assist in mitigating the risk behaviors associated with pursuits. Recommendations include assessment, management and accountability, risk behavior management, developing effective pursuit policy, compliance with pursuit policy and enhancing pursuit training practices.

Alpert and Dunham (1990) set the stage for the pursuit policy recommendations. They suggest that a four-stage process be established by law enforcement agencies. This process includes the following four components: 1) the establishment of a comprehensive pursuit policy, 2) comprehensive and practical pursuit training, 3) adequate supervision and monitoring of pursuits and 4) ownership and accountability of those involved. Based upon the results of this study, pursuit literature and review of KSP Pursuit and Emergency Response Driving policy, the following specific recommendations are offered to the KSP. 


\section{$\underline{\text { Annual Pursuit Evaluation }}$}

Hutson et al. (2007) suggested that all law enforcement agencies conduct an annual evaluation of all pursuit-related statistical information collected by the agency for a thorough analysis. Annual reviews are currently being conducted by the KSP which collects pursuit data with this intent. However, these annual evaluations should include improved categorical data collection including many of the areas addressed in the literature and included in the study. These additional categories may include characteristics of the suspect and LEO, environmental factors, vehicle information and contributing factors involved in pursuit-related collisions and injuries. Further, national data can provide valuable information regarding collisions, safety-related behaviors, and other transportation matters which may prove beneficial in the examination of pursuits (Fridell, 2004). These annual pursuit evaluations are not always conducted in a timely manner by the KSP. Efforts should be made to ensure these annual evaluations are completed on schedule and any findings are disseminated promptly to all personnel of interest.

\section{Proper Pursuit Mentality}

This study did not assess the mental state of each LEO engaged in the pursuit however, this has been a focus of some research. For some LEOs, mental aspects such as maturity and attitude have also been noted as important factors in collision reduction. Chu (2016) suggests that younger LEOs should be paired with senior LEOs as a form of informal supervision during emergency situations and pursuits. Senior LEOs are likely to 
possess maturity and be more skillful in evaluating risk during these situations. Based upon his research in Illinois, Auten (1991) suggested that practical behind-the-wheel training was important but the more important aspect in collision reduction is instilling the proper driver attitude (Auten, 1991). Pairing officers is not a reasonable option for state police agencies however addressing the driving culture and associated attitudes are.

Alpert (1996) found that the police experienced an adrenaline high when pursuing a suspect. This adrenaline high can lead to errors during the pursuit and the use of excessive force against the fleeing suspect when LEOs make first contact. A LEO must be conditioned to control emotion and remain in control throughout the duration of the pursuit.

Yates (2004) suggests that the "contempt of cop" mentality often prevails while engaged in pursuits. This mentality occurs when LEOs pursue with the intent to apprehend the suspect with little or no concern for public safety. A LEO's attitude and disposition is extremely important to efficiency in all aspects of policing (Yates, 2004) including decreasing collisions. The KSP should continue to promote a proper driver attitude and create a culture which values the safe operation of patrol vehicles.

\section{Decision-Making}

Equally important as a LEO's maturity and attitude is their ability to make sound decisions. The decision-making process of the LEO is often the most essential component in mitigating risk especially in agencies which leave the decision to pursue to the LEO. The decision-making process to engage in vehicular pursuits may include the following: 
Decision Point One: Do the LEOs have approval to initiate a pursuit?

- This decision may be based upon agency policy or procedures governing authority to initiate a pursuit.

Decision Point Two: Should the pursuit continue beyond its initial moment?

- This decision may be also be influenced by agency policy, the totality of circumstances governing the pursuit and supervisory oversight.

Decision Point Three: Should LEOs from other agencies become involved?

- This is typically a supervisory decision based upon the necessary support and the location of the pursuit and the direction it is heading which factors into concerns of jurisdiction and authority.

Decision Point Four: What strategies, tactics, or techniques can be used to stop the fleeing vehicle?

- The decision to take appropriate action to end the pursuit is often made by the pursuing LEO, monitoring supervision in conjunction with policy and procedural mandates.

Decision Point Five: Should the pursuit be terminated?

- This decision of often the most important. It hinges upon agency policy, the expertise of those involved and risks associated with the continuation of the pursuit (Oliver \& Kirchhoff, 2017).

This is a simple illustration of the decision-making process for LEOs during a standard pursuit. These decision points may be more difficult or skewed depending on the maturity and attitude of the pursuing LEO.

While a material decision-making matrix may not be appropriate to add to a pursuit policy, they may be useful in training. The KSP could integrate a decisionmaking process to add clarity to the decision points present within a pursuit. For instance, determining when to pursue and when to terminate at pursuit. Or determining what type of pursuit intervention technique is most appropriate for the circumstances. Improved decision-making can only enhance officer safety during pursuits. 


\section{$\underline{\text { Top Speed }}$}

Driving above the speed limit is a risk behavior that should be managed in pursuit driving. While the top speed of the pursuit was not found to be significant as related to negative outcomes, most KSP pursuits were considered high speed at 66 miles per hour or greater. Five (5\%) percent of KSP pursuits were initiated for reckless driving.

Greater speeds increase the chances of being involved in a negative outcome (Abdelwanis, 2013; Alpert, 1997; Rivara and Mack, 2004; Yager et al., 2015; Yates, 2009). Under this assumption, the KSP like most law enforcement agencies should begin pursuing avenues useful in ensuring their LEOs operate at reasonable speeds during pursuits. In some instances, written policy can be used to regulate the speed traveled by LEOs by designating a reasonable point above the speed limit or authorized top speed. Continual training and education of the dangers of excessive speed may also prove useful. Not only are collisions more likely at high speeds but the injuries resulting from these collisions have the potential to be much more severe (Gustafson, 2015). Numerous sources identify speed as a contributing factor in pursuit related negative outcome therefore the KSP should continue to address speed and the exercise of reasonable control of patrol vehicles while in operation.

\section{$\underline{\text { Officer Distraction }}$}

This study was unable to ascertain any measure suitable to measure the level of distraction experienced by KSP personnel involved in pursuits. However, research 
suggests that a strategy should be employed by law enforcement agencies which limits distraction experienced by LEOs engaged pursuits (Gustafson, 2015).

Some authors suggest that human beings are unable to focus on more than one thing at a time (James \& Vila, 2012). Agencies like the KSP should establish restrictions on the use of devices which might divert attention away from the pursuit such as cellular phones. Further, LEOs are often required to relay information about the pursuit to telecommunicators. Installing technology like GPS trackers and black box transmitter technology may prove useful in decreasing the need for a LEO to relay as much information during an active pursuit. This may not be a reasonable solution for many agencies due to the associated costs of technology. However, any means of eliminating distractions which may be diverting a LEO's attention to anything other than vehicle operation and the vehicle being pursued would be beneficial in reducing the likelihood of negative outcomes.

\section{Officer Fatigue}

The data utilized for this study did not contain a measure that would assess the officer's fatigue however some research has been conducted to examine the impact of fatigue on officer activities. Some acknowledge that reducing the amount of fatigue LEOs experience should be another focal point (Gustafson, 2015).

Obviously, law enforcement agencies cannot control a LEOs off-duty activities including how much rest they get during off-duty hours. What they can control is how much and how often overtime is worked. Additionally, supervision can regulate work 
schedule hours such as work shift length, consecutive work days, total weekly hours and secondary employment. Management possesses the discretion to deviate from these controls when reasonable and appropriate. Fatigue management is a supervisory task and an essential one. Supervision should take a vested interest in ensuring LEOs do not suffer from fatigue which can be a major officer safety concern and contributing factor associated with collisions (President's Task Force on 21st Century Policing, 2015). Managing officer fatigue is a reasonable option for the KSP. However, low staffing levels will make this challenging.

\section{Pursuit Intervention Techniques and Technology}

Pursuit-related collisions and injuries are often a by-product of the pursuit intervention techniques. Therefore, developing and implementing effective risk management strategies has the potential to prevent negative outcomes.

The KSP primarily utilizes three types of pursuit intervention techniques for which they collect data. There are: 1) tire deflation devices, 2) rolling roadblocks and 3) legal intervention. Tire deflation devices were utilized in $(12 \%, \mathrm{~N}=154)$ of pursuit, rolling roadblocks were utilized in $(4 \%, \mathrm{~N}=16)$ of pursuits, and legal intervention was utilized in $(6 \%, \mathrm{~N}=53)$ of pursuits between 2009 and 2017. As stated, legal intervention is an intentional act and therefore negative outcomes stemming from this technique were excluded from this study. The use of tire deflation devices and rolling roadblocks were examined. This study found the use of tire deflation devices to be a statistically significant in decreasing the likelihood the pursuit ends in collision. Neither tire deflation devices nor rolling roadblocks were found to be significant as related to injuries. 
The decision to employ a pursuit intervention technique and the selections of which technique is most appropriate is extremely important in mitigating risk and the potential for negative outcomes. Overall, the best pursuit intervention tactic and risk behavior management strategy is to avoid pursuits all together. However, tire deflation devices, GPS trackers and helicopters are considered less risky.

Tire deflation devices such as "Stingers" and "Stop Sticks" are commonplace in most law enforcement agencies. They present a low-cost option to mitigate risk and are typically contained within the trunk of most patrol vehicles. They are designed to deflate vehicle tires in a controlled manner thereby ending the pursuit with limited risk of collision (Miller, 1993). Overall, tire deflation devices are one of the safest intervention techniques to employ.

GPS tracker technology has also proven to be a very effective means of mitigating pursuits. The StarChase system is a commercial off-the-shelf system which was developed and based upon the conclusion of a National Institute of Justice (NIJ) report by Alpert (1997). In this report, Alpert (1997) concluded that once tagged by StarChase and the pursuing LEOs terminate the pursuit. Then the suspect in most cases will slow within a minute as if they are free from the police (Gaither, Gabriele, Andersen, Healy, \& Hung, 2017). The StarChase system includes a control panel which is assessable from inside the LEO's vehicle. From this control panel, a LEO can arm, aim and fire as GPS tracker device at the fleeing vehicle. Once the GPS tracker is in place, the pursuit can be terminated allowing LEOs to locate the fleeing vehicle in a safer manner. In a study of 36 agencies, Alpert (1997) found the StarChase system to be successful more than 80 percent of the time in leading police to suspects. Weather was determined to be a factor 
in unsuccessful deployments of the StarChase system (Gaither et al., 2017; Oliver \& Kirchhoff, 2017).

Helicopters provide the ability to track a pursued vehicle from the air allowing pursuit units to maintain a safe distance and trail speed. This allows agencies to promote public safety while monitoring the fleeing vehicle and eventually apprehending the suspect in a safer manner (Oliver \& Kirchhoff, 2017).

Other intervention techniques, which are considered more risky exist for LEOs as well. Boxing, channeling and the Grappler system are some of these pursuit intervention techniques. Some agencies such as the KSP utilize techniques similar to boxing and channeling and refer to them as rolling roadblocks.

The boxing technique occurs when LEOs surround the suspect vehicle with their patrol vehicles to restrict movement. Channeling involves creating the illusion of an escape route for the suspect vehicle which is in reality a pathway to a designated "take down" location. In creating this illusion, LEOs direct the suspect to a location such as a parking lot, unpaved area or dead end by way of barriers such as their pursuit vehicles, tractor-trailers or barricades. Once these barriers are in place, the suspect sees the singular unobstructed "escape route" which they voluntarily accept before ultimately being corralled in a safer location designated for apprehension (Miller, 1993).

Another form of more risky pursuit intervention is the Grappler Police Bumper system (Grappler). The Grappler is a device which is attached to the front bumper of a police vehicle. When ready to deploy, the LEO must close in on the rear of the suspect vehicle. When in position, the LEO will lower the Grappler device and drive it into the rear wheel (s) of the suspect vehicle. Upon contact, the netting straps from the Grappler 
device secure themselves to the rear wheel (s) and immobilizes them. This process can operate with the netting straps tethered to the police unit or they can be detached at will. The Grappler system is not without risk because it requires that the police vehicle be placed in proximity to suspect vehicle thereby increasing the chance of negative outcomes. However, this intervention technique does decrease the chance of serious negative outcomes (Grappler, 2019).

Boxing, channeling and the Grappler system are considered riskier than tire deflation devices, GPS trackers and helicopters. These techniques increase the potential for negative outcomes however, they present significantly less risk than terminating a pursuit with vehicle to vehicle use of force.

As a pursuit progresses and more information is gathered, a decision may be made that circumstances necessitate a need to terminate a pursuit by force. In this case, determining the type of force (i.e., pursuit intervention technique) to employ should be done with extreme prejudice. Vehicle to vehicle intervention techniques are considered a higher-level use of force due to the potential for serious injury or death. Once the decision is made that the pursuit must be terminated immediately, a tactical decision can be made to deploy "legal intervention" in a location likely to result in the least amount of collateral damage. Legal intervention employed by most agencies is called a Pursuit Intervention Technique (P.I.T.) or Tactical Vehicle Intervention (T.V.I.). This is an iteration of the ramming technique and is considered high risk. Ramming occurs when the pursuit vehicle intentionally drives into the suspect vehicle to make it stop (Miller, 1993). The P.I.T. technique is conducted by the pursuing LEO driving their front bumper into the rear quarter panel of the suspect's vehicle. Once contact is made, the pursuing 
LEO accelerates and turns into the suspect's vehicle. The maneuver causes a loss of tire traction. In many cases, this causes the vehicle's engine to shut down ending the pursuit. This can also result in the suspect vehicle losing traction resulting in a "spin out" thereby immobilizing the vehicle (Miller, 1993). Vehicle to vehicle intervention techniques are important to mention because of the frequency of use and its relevance this discussion. As discussed, these techniques fall outside of the scope of collisions as defined in this study because they are an intentional act by the authorities.

Each of these risk behavior management strategies and other considerations presented in this section have the potential to impact the rate of negative outcomes resulting from pursuits. The next section will examine considerations for the development of effective pursuit policy.

\section{Developing Effective Pursuit Policy}

Negative outcomes associated with vehicular pursuits may be fiscally harmful to taxpayers and law enforcement agencies alike. Law enforcement agencies value the promotion of professional standards within their ranks. A well-written pursuit policy has the potential to regulate LEO behaviors and become a useful mechanism to assist in pursuit management.

Fennessy et al. (1970) classified police pursuit policy into three different categories: 1) officer judgment model; 2) restrictive model; 3) and model of discouragement or prohibition. Territo (1982) recommended the development of a pursuit policy which implemented controls on the operation of police vehicles and other emergency equipment. 
Policy development is often driven by risk management and liability concerns (Alpert and Smith, 1994). Policy can be defined as: a course of action or inaction chosen by public authorities to address a given problem or interrelated set of problems. Policy is a course of action that is anchored in a set of values regarding appropriate public goals and a set of beliefs about the best way of achieving those goals. (Pal, 2001).

Modifications to pursuit policy should also be considered as a means of enhancing pursuit response. Policy modification may increase or decrease the potential for pursuits relative to the language contained within (Alpert, 1997; Alpert, Kenney, Dunham, \& Smith, 2000). Alpert (1997) noted that pursuits decreased in Miami-Dade when, in 1992, they amended their policy to restrict pursuits to violent felonies only. Their pursuit totals dropped 82 percent and subsequently collisions and injuries also decreased. Conversely, Omaha amended their policy to allow pursues to be initiated solely at the LEO's discretion in 1993. This resulted in a 600 percent increase in pursuits within the first year of implementation. Clearly, policy can have a significant impact on the frequency of pursuits. The KSP operates under the premise of trooper discretion like Omaha does.

Setting clear parameters for pursuit driving is extremely important. Not only can pursuit policy regulate speed, but it can also offer guidelines for all types of response driving. Parameters should be set regarding how, when, and where pursuits are authorized. Policy should be extremely specific covering the guidelines for initiating and terminating pursuits, the number of police units involved, the use of intervention techniques, and firearm usage (Hess \& Wrobleski, 2006). Training for LEOs regarding these standards should be provided once they are developed. LEOs will benefit from 
consistency and standardization of driving expectations (Gustafson, 2015) during a pursuit.

For law enforcement agencies, pursuit policy can vary from one end of the spectrum to the other. Some have adopted a "chase-them-all" policy while others have restricted pursuits to felonies only or a "no chase" policy (Hess \& Wrobleski, 2006). The development of a nationwide pursuit policy has been proposed by some but is not probable due to the vastness and diversity of the United States (Hicks, 2006).

Tiesman and Heick's (2014) conducted a study of pursuit policy restrictions among Iowa LEOs. They found most agencies required all LEOs to wear seatbelts. They also found additional restrictions regarding vehicle speed and the use of mobile phone and similar devices while operating a vehicle. Sharp (2003) surveyed 30 randomly selected law enforcement agencies of varying sizes. Sharp found that 83 percent of these agencies restricted a LEO's ability to engage in a pursuit. Ninety-three percent limited the number of police vehicles allowable in the pursuit to not more than two.

The KSP currently has a well-written comprehensive pursuit policy. While it is unreasonable to expect any pursuit policy to address every possible contingency, their policy does provide guidance in most areas. It regulates where pursuits are authorized, the number of police units permitted, restricted zones, parameters for termination and requirements for supervisor approval. Overall, KSP's General Order OM-B-15 Pursuit and Emergency Response Driving, OM-B-15a Legal Intervention \& Tire Deflation Devices, and OM-B-14 Roadblocks policy would be considered less restrictive by most standards. Further, it allows for considerably officer discretion regarding pursuits. Considering that the rates of collisions and injuries have been trending upward since 
2009, it may be prudent for KSP leadership to examine all aspects of KSP pursuit practices including policy. The KSP could provide more specific language as deemed appropriate by the KSP legal staff involving acceptable speed parameters, criteria for initiating a pursuit and decision-making regarding the appropriate use of pursuit intervention techniques. It is not enough for law enforcement agencies to detail these instructions in policy. LEO's must adhere to these policies for them to be effective.

\section{Compliance with Pursuit Policy}

While pursuit policy development is extremely important, it does little to effect positive change if it is not understood and adhered to. Further, under-reporting the initiation of pursuits by LEOs seems to be the most significant administrative concern when policies become more restrictive. Therefore, it is recommended that sanctions be detailed in policy and imposed for those LEOs who violate pursuit guidelines (Payne \& Fenske, 1997).

The nature of police work requires most LEOs to work autonomously without direct oversight from supervision. This has the potential to lead to problems in ensuring compliance with policy (Rubinstein, 1973). Hansen, Rojek, Wolfe, and Alpert, (2015) conducted a study to assess the potential of the imposition of discipline for violations of agency driving policy resulting in vehicular collisions. The logic behind this study was

deterrent-based in nature and built upon the work of White (2001). The findings support Alpert and Dunham's (1990) recommendation for ownership and accountability.

Over time as pursuit policies have become more restrictive, LEOs who believe their ability to engage in vehicular pursuits and apprehend violators is an essential 
component in crime-fighting may be more resistant in complying with restrictive pursuit policy. Whether more stringent policies result in non-compliance is an important determination to be made. This determination is important for two reasons: 1) litigation against a department typically involves the lack of adherence to policy and 2) pursuit management improvement including reporting can decrease negative implications (Crew et al., 1994). Some are concerned with accurate reporting procedures (Crew et al., 1995). To receive policy compliance, LEOs must be held accountable for failing to comply with assigned mandates. New policy has little chance to effect positive change if LEOs are not held accountable for failing to comply (Gustafson, 2015).

Crew et al. (1994) found that the creation of more restrictive pursuit policy will result in fewer pursuits taking place but did not increase non-compliance with requirements to report. Crew et al. (1995) found that more restrictive pursuit policies did not increase non-compliance in the requirement to report the initiation of the pursuit. Conversely, Falcone et al. (1992) found that policy amendments resulted in the underreporting of pursuit initiations in Illinois and Michigan. Similarly, Britz and Payne (1994) found substantial evidence of unreported pursuits which lead to high collisions rates in Illinois and Michigan.

In addition to the concerns regarding amendments to policy, there may be other reasons LEOs chose to under-report pursuits to supervision. A LEO's decision to report may involve: fear of discipline, fear of litigation or the awareness that agency pursuit policy has been violated (Payne \& Corley, 1994). There are mixed results whether amendments result in under-reporting. However, it can be deduced that the development of a well-written vehicular pursuit policy can present a cumulative positively effect. 
Once effective policy has been developed, it must be followed up by clear and concise training for all affected personnel.

The KSP could look to establish criteria for pursuit policy violations above and beyond their current standards of conduct. But this would be contingent upon the agency determining that a more restrictive pursuit policy is warranted.

\section{Developing an Effective Pursuit Training Program}

Pursuit training in an important aspect of safe vehicle operation during a pursuit and can positively impact the frequency of collisions and injuries. Simply put, training improves operator performance which impacts negative outcomes. This is especially true of highly complex tasks (Schneider, 1985). Pursuit training of the past may have contained the catch them at any cost attitude mitigated with some concern for officer safety (Kroeker \& McCoy, 1998). Later training included an emphasis on the concern for the safety of the LEO, the suspect and public safety. Initial training focused on physical skills orientation (Basham, 1978; Clark, 1976; Dougherty, 1961; International Association of Chiefs of Police (IACP), 1965, 1968; Schultz, 1979; \& Traffic Institute, 1981). Training later evolved to include an emphasis on policy concerns, restrictions and additional skills development (Auten, 1985; Auten, 1991; Fyfe, 1989; Halloran, 1985).

Although pursuits are considered high risk, pursuit training by departments is sparse or non-existent. Alpert (1997) found that 60 percent of the agencies provide basic pursuit training while in the academy, but little else afterwards. Post academy training for vehicular pursuits averaged just over three hours annually. He also found that midsize departments (501 to 2,500 LEOs) provided less pursuit training than smaller 
departments yet experienced more pursuit-related collisions (Alpert, 1997). This is consistent with the KSP which only provides pursuit training during basic academy training.

Proficiency in driving requires both skills training and cognitive conditioning such as psychomotor skills and decision-making abilities (Dorn, 2010; Dorn \& Barker, 2005). LEOs that engage in risk-taking behaviors while driving may contribute to negative outcomes. The University of Illinois study conducted by Auten (1991) referenced earlier in this paper concluded with a need "... to expand upon the currently existing body of knowledge concerning police pursuit driving operations" (Auten, 1991, p. 13). In his findings, Auten (1991) determined that for police driver training courses to be effective, they should include practical exercises which includes rigorous behind-thewheel exercises. Similarly, in a study conducted by the United States Department of Transportation they concluded that training needed to be comprehensive including practical as well as classroom instruction (Charles \& Falcone, 1992). Emergency Vehicle Operations Course (EVOC) with a pursuit response driving component and even driving simulators can fulfill this recommendation.

While training and technology are extremely important in orchestrating an effective pursuit, emotional control and mental preparation is also integral. Auten (1991) also emphasized the need to instill recruits and experienced LEOs with the proper attitude. Abbott (1988) argued that more collisions result from LEOs which possess an improper driver attitude than from their lack of driver skill. Likewise, Daniels and Spratley (2003) stated that in terms of training, the single most important skill is a LEO's 
mindset and ability to think ahead and consider options for safely ending the pursuit (Daniels \& Spratley, 2003).

Utilizing pursuit continuums and conducting mental and practical training using these continuums is one way to develop a standard mindset in LEOs. Some departments utilized such continuums to align the options available to LEOs engaged in a pursuit in relation to the threat posed by the suspect being pursued. One such continuum, the Pursuit Management Continuum was developed by Ashley (2000). This continuum accounted for and labeled the known threat posed by the suspect and the corresponding control level of the LEO into three categories from the least to greatest (Ashley, 2000).

Some departments such as the KSP do not adhere steadfast to a continuum of "acceptable" behaviors and actions as a component of pursuit management. Some agencies leave pursuit decisions to the discretion of the LEO and supervision involved in the pursuit (LEMAS, 2013; Reaves, 2017). Further, establishing pursuit continuums and requiring agency staff to adhere to the continuum via policy can open an agency up to legal liability and scrutiny if a LEO is required to deviate from the set standards based on a spur-of-the-moment decision (Ashley, 2000).

When training an officer to pursue, serious consideration should be given to the perspective presented by Alpert (1997) and Dunham, Alpert, Kenny, and Cromwell (1998). They argue that in most instances, the absence of "pressuring" will result in the suspects either slowing or stopping once they no longer feel that they are being pursued. Pressuring occurs as a result of being actively involved in a pursuit and subjected to the psychological stresses felt as a result of the flashing lights, blaring sirens and heightened emotional state (Best, 2005). If a means of tracking the suspect is available, knowledge 
of the effects of pressuring can present a safer means to pursuit resolution for all parties involved. Clearly, this should become a focal point in pursuit training, so it can be factored into the calculus of LEOs and supervisors involved in or monitoring a pursuit.

Proficiency in police-related skills such as driving, and firearms usage are diminishable and require training to maintain or improve proficiency. Without consistent and repeated training, these skills weaken over time (Yates, 2004). Some may argue agencies lack the time or resources to conduct the appropriate levels of training for their LEO. When comparing pursuit response driver training to mandatory firearms training, the likelihood of being involved in either incident is relatively equal. However, driver training for vehicular pursuits is rarely conducted after basic academy training. Yet LEOs spend a considerable amount of their time operating a vehicle. Conversely, firearms training is conducted at least annually by most law enforcement agencies and LEOs rarely discharge their firearm.

The KSP conducts over 40 hours of practical high-speed emergency response and pursuit driver training during basic academy training. This training is conducted at the NCM Motosports Park Speedway in Bowling Green Kentucky. The KSP does not currently offer any pursuit training after the academy. It is recommended that the KSP provide practical and comprehensive pursuit training on a reoccurring basis.

\section{LIMITATIONS AND FUTURE STUDIES}

This study could have been more robust if it included a larger span of years. The inclusion of additional data could present a clearer picture of the trends under examination. Additionally, there were limits in the quality and consistency of the data 
collected and utilized in this study. This limitation became apparent when creating the data set for this study. It was determined that some data was missing from the annual SPB spreadsheets which may have occurred for a couple of reasons. This could have occurred because all the data collected from the Teletypes was not transposed on to a spreadsheet by the SPB. Or, certain pursuit data was not requested through the CAD Teletype template for a certain year and therefore was not collected and available to be added to the SPB spreadsheet. The data set created for this study was largely developed from the data collected on the annual SPB spreadsheets.

For these reasons, the total number of pursuits examined in this study does not match the total number of pursuits occurring for the year 2011. There were a total 116 pursuits that occurred in 2011 while only 108 are represented in this data set. Each of the totals for the other years under study matched exactly.

Further, several years from 2009 to 2014 do not contain the same CAD Teletype template categories therefore some data was not collected consistently each year. Calendar years 2012-2014 did not contain the category "Rolling Road Block Used". Calendar year 2011 did not contain the categories: Subject Resisted Arrest; Subject Fled after Traffic Stop; Subject Died; Rolling Road Block Used. Calendar year 2010 did not contain categories: Subject Resisted Arrest; Subject Fled after Traffic Stop; Subject Died; Rolling Road Block Used and Injuries Sustained. Calendar year 2009 did not contain many categories including Subject Resisted Arrest; Subject Fled after Traffic Stop; Subject Died; Rolling Road Block Used; Injuries Sustained; Subject Fled on Foot; Legal Intervention was Used; Duration of the Pursuit; Termination of the Pursuit; Reason for Termination of the Pursuit. 
Another limitation of this study was the absence of identifying characteristics pertaining to the suspects or the officers involved in the pursuits. Officer and suspect characteristics were not included in this study because this information was not available. The only identifying characteristics collected by the KSP was the LEO's name and whether the suspect was a juvenile. Therefore, no specific individual data was included in this study.

This study can serve as a basis for future studies involving the KSP or other law enforcement agencies. Future studies with the KSP should include a larger span of years, more consistent categorical data collection from year to year, the collection of categorical data addressed in the literature, and the collection of some identifying characteristics of those involved. The additional categorical data suggested in the literature may include measures for the LEO's mental state (i.e., driver attitude) during the pursuit, an assessment of the LEO decision-making during the pursuit, any distraction experienced by the LEO during the pursuit and whether the LEO was fatigued prior to initiating the pursuit.

\section{CONCLUSION}

In conclusion, law enforcement agencies are likely to continue engaging in vehicular pursuits for any number of reasons. Therefore, a certain amount of risk is unavoidable. However, when law enforcement agencies take risk seriously and entertain opportunities to minimize those identified risks, a higher level of safety may be obtained. Conclusions have been drawn from the findings of this study which address the research questions. 
In response to research question number one, the finding from this study indicates an upward trend in the amount of pursuit-related collisions and pursuit-related injuries. Results of this kind do not provide a definitive answer regarding why there is an upward trend. They only confirm the direction of the trend. Further study is required to determine potential causes for this upward trend in pursuit-related collision and injuries within the KSP.

Research question two identified the contributing factors found to be predictors of collisions. This study concluded that having three or more units involved in a pursuit increases the likelihood for collision. It was also determined that the use of tire deflation devices decrease the likelihood for pursuit to end in collision. None of the selected predictors were significant regarding injuries.

KSP policy currently contains language restricting pursuits to a "maximum of two (2) agency vehicles in immediate pursuit". For a significant decrease in collisions and injuries to occur within the KSP, risk management strategies should be employed by the KSP to examine the identified statistically significant contributing factor and others identified in the literature. The following areas were identified as potential risk management strategies: 1) mitigate contributing factors and risk behaviors to what extent possible during pursuits; 2) expand upon and examine the need to make pursuit policy more comprehensive and restrictive based upon the needs of the agency which may include limiting officer discretion; 3) conduct practical pursuit training on a reoccurring basis; 4) improve pursuit monitoring by supervision to ensure compliance with policy; and 5) increase accountability by LEOs found to have violated pursuit policy. 
As with most initiatives for process improvement, training and education is a starting point. Pursuit training must include educating all personnel on the agency pursuit policy once it has been revised and approved. Emergency response driving may also be a main component of this training. Similar to pursuit driving, emergency response driving is a diminishable skill. Therefore, providing proficient and continual training is paramount to ensure all personnel possess the driver skill, proper driver attitude, and knowledge essential to ensuring safe, yet effective vehicle pursuit practices. Enhanced supervisor oversight of pursuits and officer accountability is important in ensuring responsible actions are taking and that those exhibiting irresponsibility are held accountable. Otherwise, implementing positive change has little chance of success. Pursuit operations should seamlessly meld with policy and training. Employing pursuit intervention techniques are also an area requiring attention. As noted, some techniques present a high likelihood than others for collisions and injuries to occur. Lastly, the safety of the officer and safety of the public should remain the primary concern in pursuit operations. When this focus shifts to other areas, or a subculture exists within law enforcement agencies which contradicts this ideal, the potential exists for a law enforcement agency to experience increasing trends in pursuit-related collisions and injuries. 


\section{REFERENCES}

Abbott, L. (1988). Pursuit driving. FBI L. Enforcement Bull., 57, 7.

Abdel-Aty, M. (2003). Investigating the relationship between cellular phone use and traffic safety. Institute of Transportation Engineers. ITE Journal, 73(10), 38.

Abdelwanis, N. (2013). Characteristics and contributing factors of emergency vehicle crashes (Doctoral dissertation, Clemson University).

Alpert, G. P. (1996). Life, Liberty and Pursuits. Law Enforcement News. December 31, 1996, 26.

Alpert, G. P. (1997). Police pursuit: policies and training. US Department of Justice, Office of Justice Programs, National Institute of Justice.

Alpert, G. P. (1998). A factorial analysis of police pursuit driving decisions: A research note. Justice Quarterly, 15(2), 347-359.

Alpert, G. P., \& Anderson, P. R. (1986). The most deadly force: Police pursuits. Justice Quarterly, 3(1), 1-14.

Alpert, G. P., \& Dunham, R. G. (1988). Research on police pursuits: Applications for law enforcement. Am. J. Police, 7, 123.

Alpert, G. P., \& Dunham, R. G. (1989). Policing hot pursuits: The discovery of aleatory elements. J. Crim. L. \& Criminology, 80, 521.

Alpert, G. P., \& Dunham, R. G. (1990). Police pursuit driving: Controlling responses to emergency situations. Westport, CT: Greenwood Press.

Alpert, G. P., \& Fridell, L. A. (1992). Police vehicles and firearms: Instruments of deadly force. Prospect Heights, IL: Waveland Press.

Alpert, G. P., \& Madden, T. (1994). Police pursuit driving: An empirical analysis of critical decisions. Am. J. Police, 13, 23.

Alpert, G. P. \& Smith, W. C. (1994). Developing police policy: an evaluation of the control principal. American Journal of Police, 13(2), 1-20.

Alpert, G. P., Kenney, D., Dunham, R., \& Smith, W. (2000). Police pursuits: What we know. In Police Executive Research Forum, Washington, DC. 
Ashley, S. (2000). Pursuit Management Continuum. http://www.sashley.com/articles/pursuit_management_continuum bw.htm

Auten, J. H. (1989). Law enforcement driving. CC Thomas.

Auten, J. H. (1991). Police pursuit driving operations in Illinois: 1990. University of Illinois, Police Training Institute.

Auten, J. (1994). Police pursuits and officer attitude: Myths and realities. American Journal of Police.

Basham, D. J. (1978). Traffic law enforcement. Thomas.

Batiste, J. R., Wagers, M. L., \& Ashton, R. J. (2011). Preventing traffic-related line-ofduty deaths. The Police Chief, 78(July), 52-55.

Beckman, E. (1983). High speed chases: in pursuit of a balanced policy. Police Chief, 50(HS-036 222).

Beckman, E. (1986). Pursuit driving: A report to law enforcement on factors in police pursuits. Michigan Police Chiefs Newsletter, 26, 34.

Bener, A., Lajunen, T., Özkan, T., \& Haigney, D. (2006). The effect of mobile phone use on driving style and driving skills. International Journal of Crashworthiness, 11(5), 459465 .

Best, D., \& Eves, K. (2005). Why are there no lessons learned from road traffic incidents involving the police?. Criminal justice, 5(1), 37-53.

Borrello, A., (2001). Managing Risk for Non-Risk Managers Practical Perspectives for Police Professionals. http://neiassociates.org/managing-risk/

Britz, M. T., \& Payne, D. M. (1994). Policy implications for law enforcement pursuit driving. Am. J. Police, 13, 113.

Castro, C. (2008). Human factors of visual and cognitive performance in driving. CRC Press.

Chamlin, M. B. (1988). Crime and arrests: An autoregressive integrated moving average (ARIMA) approach. Journal of Quantitative Criminology, 4(3), 247-258.

Charles, M. T., \& Falcone, D. N. (1992). Illinois police officers' opinions on police pursuit issues. Am. J. Police, 11, 69.

Chu, H. C. (2016). Risk factors for the severity of injury incurred in crashes involving on-duty police cars. Traffic injury prevention, 17(5), 495-501. 
Clark, J. M. (1976). Emergency and high speed driving techniques. Gulf Publishing Company, Book Division.

Crew, R. E., \& Hart, R. A. (1999). Assessing the value of police pursuit. Policing: An International Journal of Police Strategies \& Management, 22(1), 58-74.

Crew Jr, R. E., Kessler, D., \& Fridell, L. A. (1994). Changing hot pursuit policy: an empirical assessment of the impact on pursuit behavior. Evaluation Review, 18(6), 678688.

Crew Jr, R. E., Kessler, D. A., \& Fridell, L. A. (1995). Compliance with hot pursuit policy. Evaluation Review, 19(5), 513-519.

Daniels, W., \& Spratley, L. (2003). Brainpower not horsepower: Teaching officers when and how to end pursuits. Law and Order, 51(7), 85-89.

Dawson, D., \& Reid, K. (1997). Fatigue, alcohol and performance impairment. Nature, 388(6639), 235.

Dorn, L. (2005). Driver behaviour and training Vol. 2. Routledge.

Dorn, L. (2010). Driver behaviour and training Vol. 4. Routledge.

Dorn, L., \& Barker, D. (2005). The effects of driver training on simulated driving performance. Accident Analysis \& Prevention, 37(1), 63-69.

Dougherty, E. E. (1961). Safety in police pursuit driving. Thomas.

Dunham, R. G., Alpert, G. P., Kenny, D. J., \& Cromwell, P. (1998). High-speed pursuit: The offenders' perspective. Criminal Justice and Behavior, 25(1), 30-45.

Falcone, D. N. (1994). Police pursuits and officer attitudes: Myths and realities. Am. J. Police, 13, 143.

Falcone, D., Wells, E., \& Charles, M. (1992). Police pursuit in pursuit of policy: The empirical study. Washington, DC: AAA Foundation for Traffic Safety.

Federal Bureau of Investigation. (2008). Law Enforcement Officers Killed and Assaulted, 2008.

Federal Signal. (2017). Stinger XL Tire Deflation Device. https://www.fedsig.com/product/stinger\#product-block-2

Fennessy, E. F., Hamilton, T., Joscelyn, K. B., \& Merrit, J. S. (1970). A Study of the Problem of Hot Pursuit by the Police. 
Fennessy Jr, E. F., \& Joscelyn, K. B. (1971). A national study of hot pursuit. Denv. LJ, $48,389$.

Fridell, L. A. (2004). By the numbers: A guide for analyzing race data from vehicle stops. Washington, DC: Police Executive Research Forum.

Friedman, L. S., Hedeker, D., \& Richter, E. D. (2009). Long-term effects of repealing the national maximum speed limit in the United States. American Journal of Public Health, 99(9), 1626-1631.

Fyfe, J. J. (1989). Controlling police vehicle pursuits. International City Management Association, Washington DC.

Gaither, M., Gabriele, M., Andersen, N., Healy, S., \& Hung, V. (2017). Pursuit Technology Impact Assessment, Version 1.1.

Garber, N. J., \& Gadiraju, R. (1992). Impact of differential speed limits on the speed of traffic and the rate of accidents. Transportation Research Record, (1375).

Grappler. (2019). Grappler Police Bumper. www.policebumper.com/

Greenberg, D. F., Kessler, R. C., \& Logan, C. H. (1979). A panel model of crime rates and arrest rates. American Sociological Review, 843-850.

Greenberg, D. F., \& Kessler, R. C. (1982). The effect of arrests on crime: A multivariate panel analysis. Social Forces, 60(3), 771-790.

Gustafson, B. G. (2009). Driver Training Study: Volume I. Commission on Peace Officer Standards and Training, Sacramento, CA.

Gustafson, B. G. (2015). Then \& now: trends in fatal law enforcement traffic collisions. Policing: An International Journal of Police Strategies \& Management, 38(3), 407-424.

Gustafson, B. G., \& Cappitelli, P. A. (2010). SAFE driving: the role of the chief. The Police Chief, 77(3), 38-41.

Halloran, J. (1985). Driving programs teach safer, yet quicker pursuit. Law and Order, 33(3), 18-21. 
Hannigan, M. (1992). The viability of police pursuits. The Police Chief, 59(46), 48-49.

Hansen, J. A., Rojek, J., Wolfe, S. E., \& Alpert, G. P. (2015). The influence of department policy and accountability on officer-involved collisions. Policing: An International Journal of Police Strategies \& Management, 38(3), 578-594.

Hess, K., Orthmann, C. H., \& Cho, H. (2014). Introduction to law enforcement and criminal justice. Nelson Education.

Hess, K., \& Wrobleski, H. M. (2006). Police operations: Theory and practice. Thomson Wadsworth.

Hicks, W. L. (2006). Police vehicular pursuits: a descriptive analysis of state agencies' written policy. Policing: An International Journal of Police Strategies \& Management, 29(1), 106-124.

Homant, R. J., Kennedy, D. B., \& Howton, J. D. (1994). Risk taking and police pursuit. The Journal of Social Psychology, 134(2), 213-221.

Hutson, H. R., Rice Jr, P. L., Chana, J. K., Kyriacou, D. N., Chang, Y., \& Miller, R. M. (2007). A review of police pursuit fatalities in the United States from 1982-2004.

Prehospital emergency care, 11(3), 278-283.

Insurance Information Institute (1997). American Insurance Industry, https://www.iii.org/.

International Association of Chiefs of Police (1965). Safe Driving Techniques (Training Key \#20), Washington, DC.

International Association of Chiefs of Police (1968). Pursuit Driving, (Training Key \#92). Washington, DC.

International Association of Chiefs of Police (2011). Preventing Traffic-Related Line-ofDuty Deaths. International Association of Chiefs of Police. Alexandria, VA.

James, S. M. \& Vila, B. (2012). "Driven to distraction". Journal of California Law Enforcement, 46(2), 14-18.

Johnson, R. R. (2013). A longitudinal examination of officer deaths from vehicle pursuits. International Journal of Police Science \& Management, 15(2), 77-94.

Kappeler, V. E. (2006). Critical issues in police civil liability. Waveland Press.

Kappeler, V. E., Kappeler, S. F., \& Del Carmen, R. V. (1993). A content analysis of police civil liability cases: Decisions of the federal district courts, 1978-1990. Journal of 
Criminal Justice, 21(4), 325-337. Kappeler, V. E., Sluder, R. D., \& Alpert, G. P. (1994). Forces of Deviance: The Dark Side of Policing. Prospect Heights, IL.

Kentucky State Police (KSP). (2018). http://kentuckystatepolice.org/fallenmemorial/

Ko, Michael (2004). Harborview Researchers Tally Police Chase Toll. Seattle Times, April 8, 2004.

Kroeker, M., \& McCoy, C. (1988). Establishing and implementing department policies. The Police Chief, (December, 1988), 36.

LaTourrette, T. (2015). Risk factors for injury in law enforcement officer vehicle crashes. Policing: An International Journal, 38(3).

Law Enforcement Management and Administrative Statistics (LEMAS) (2013). Bureau of Justice Statistics.

Lockie, R. G., Dawes, J. J., Kornhauser, C., Holmes, R. J., \& Orr, R. M. (2018).Young Officers Drive Faster, but Older Officers Crash Less: Results of a Police Pursuit Driving Course. We aim to make evidence based methodology part of everyday policing in Australia and New Zealand, 37.

Loukopoulos, L. D., Dismukes, R. K., \& Barshi, I. (2016). The multitasking myth: Handling complexity in real-world operations. Routledge.

Masters, R., Way, L. B., Gerstenfeld, P. B., Muscat, B. T., Hooper, M. K., Dussich, J. P., Pincu, L., \& Skrapec, C. A. (2011). CJ: Realities and challenges. McGraw-Hill Education.

McCartt, A. T., Hellinga, L. A., \& Bratiman, K. A. (2006). Cell phones and driving: review of research. Traffic injury prevention, 7(2), 89-106.

Medical Dictionary (MD). (2018). The Free Dictionary. https://medicaldictionary.thefreedictionary.com/motor+vehicle+accident

Miller, M. R. (1993). Police Patrol Operations. Copperhouse Publishing Company.

Miller, T. R. (1990). The Plausible Range for the Value of Life-Red Herrings Among the Mackerel. Journal of Forensic Economics, 3(3), 17-39.

Morris, E. R. (1993). Modifying Pursuit Behavior: The 9Ts Approach. FBI L. Enforcement Bull., 62, 1.

National Highway Traffic Safety Administration (NHTSA) (2004). Definitions of Pursuits (In House Definitions. Washington, DC: US Department of Transportation. Fatality Analysis Reporting System. 
National Highway Traffic Safety Administration (NHTSA) (2010). Characteristics of Law Enforcement Officers' Fatalities in Motor Vehicle Crashes (DOT HS 811 411). National Highway Traffic Safety Administration. Washington, DC.

National Highway Traffic Safety Administration (NHTSA) (2011). Characteristics of Law Enforcement Officers' Fatalities in Motor Vehicle Crashes (DOT HS 811 411). National Highway Traffic Safety Administration. Washington, DC.

National Institute for Occupational Safety and Health (2009), National Occupational Research Agenda (NORA): National Public Safety Agenda for Occupational Safety and Health Research and Practice in the US Public Safety sub Sector, National Institute for Occupational Safety and Health, Washington, DC.

National Law Enforcement Officers Memorial Fund (NLEOMF) (2009), Law Enforcement Officer Deaths: Preliminary 2009: A Tale of Two Trends: Overall Fatalities Fall, Fatal Shootings on the Rise (Research Bulletin), National Law Enforcement Officers Memorial Fund, Washington, DC.

National Law Enforcement Officers Memorial Fund (NLEOMF) (2014), Law Enforcement Officer Deaths: Preliminary 2009: A Tale of Two Trends: Overall Fatalities Fall, Fatal Shootings on the Rise (Research Bulletin), National Law Enforcement Officers Memorial Fund, Washington, DC.

National Safety Council (NSC) (2007). American National Standards Manual on Classification of Motor Vehicle Traffic Accidents $7^{\text {th }}$ Edition. Washington, DC: US Department of Transportation. Fatality Analysis Reporting System.

Nugent, H., Connors III, E. F., McEwen, J. T., \& Mayo, L. (1990). Restrictive policies for high-speed police pursuits. Washington, DC: National Institute of Justice.

Oliver, P., \& Kirchhoff, S. (2017). Managing High-Speed Pursuits. Police.

Pal, L. (2001). Beyond Policy Analysis: Public Issue Management in Turbulent Times Toronto: ITP Nelson.

Pallant, J. (2013). SPSS survival manual. McGraw-Hill Education (UK).

Payne, D. M., \& Corley, C. (1994). Police pursuits: Correlates of the failure to report. Am. J. Police, 13, 47.

Payne, D. M., \& Fenske, J. C. (1997). An analysis of the rates of accidents, injuries and fatalities under different light conditions: A Michigan emergency response study of state police pursuits. Policing: An International Journal of Police Strategies \& Management, 20(2), 357-373. 
Pipes, C., \& Pape, D. (2001). Police pursuits and civil liability. FBI L. Enforcement Bull., $70,16$.

President's Task Force on 21st Century Policing. (2015). Interim Report of the President's Task Force on 21st Century Policing, Office of Community Oriented Policing Services, Washington, DC.

Reaves, B. A. (2017). Police Vehicle Pursuits, 2012-2013.

Rice, T. M., Troszak, L., \& Gustafson, B. G. (2015). Epidemiology of law enforcement vehicle collisions in the US and California. Policing: An International Journal of Police Strategies \& Management, 38(3), 425-435.

Rivara, F. P., \& Mack, C. D. (2004). Motor vehicle crash deaths related to police pursuits in the United States. Injury Prevention, 10(2), 93-95.

Rosen, C. (2008). The myth of multitasking. The New Atlantis, (20), 105-110.

Rubinstein, J. (1980). City police. Macmillan.

SAS Institute Inc. (SAS). (1999). SAS OnLineDoc. Version 8, Cary, NC: SAS Institute Inc.

Schneider, W. (1985). Training high-performance skills: Fallacies and guidelines. Human factors, 27(3), 285-300.

Schultz, D. O. (1979). Police pursuit driving handbook. Gulf Pub., Book Division.

Schultz, D. P., Hudak, E., \& Alpert, G. P. (2009). Emergency driving and pursuits: The officer's perspective. FBI L. Enforcement Bull., 78, 1.

Sharp, A. (2003). The dynamic of vehicle chases in real life. Law and Order, 51(7), 6874.

Stop Stick. (2019). https://stopstick.com/products/stop-stick

Territo, L. (1982). Citizen safety: Key element in police pursuit policy. Trial, 18(8), 3034.

Tiesman, H. M., \& Heick, R. J. (2014). Law enforcement officer motor vehicle safety: findings from a statewide survey.

Traffic Institute. (1981). Pursuit in Traffic Law Enforcement.

White, M. D. (2001). Controlling police decisions to use deadly force: Reexamining the importance of administrative policy. Crime \& Delinquency, 47(1), 131-151. 
Williamson, A. M., Feyer, A. M., Mattick, R. P., Friswell, R., \& Finlay-Brown, S. (2001). Developing measures of fatigue using an alcohol comparison to validate the effects of fatigue on performance. Accident Analysis \& Prevention, 33(3), 313-326.

Wolfe, S. E., Rojek, J., Alpert, G., Tiesman, H. M., \& James, S. M. (2015).

Characteristics of officer-involved vehicle collisions in California. Policing: An International Journal of Police Strategies \& Management, 38(3), 458-477.

Vila, B. (2000). Tired cops: The importance of managing police fatigue. Washington, DC: Police Executive Research Forum.

Vila, B. (2006). Impact of long work hours on police officers and the communities they serve. American journal of industrial medicine, 49(11), 972-980.

Vila, B. (2009). Sleep deprivation: What does it mean for public safety officers. NIJ Journal, 262, 26-31.

Vila, B., \& Gustafson, B. G. (2011). The ongoing crisis: Officer-involved collisions-why they happen and what can be done. California Peace Officer, 12-13.

Vito, G. F., \& Blankenship, M. B. (2002). Statistical analysis in criminal justice and criminology: A user's guide. Prentice Hall.

Yager, C., Dinakar, S., Sanagaram, M., \& Ferris, T. K. (2015). Emergency Vehicle Operator On-Board Device Distractions. Texas A\&M Transportation Institute Technical Report.

Yates, T. (2004). Law enforcement pursuits: Managing the risks. Women Policing, 38(4), $10-11$.

Yates, T. (2009). Analysis of the IACP Report: 'Police Pursuits in an Age of Innovation and Reform.'. PoliceOne.com News.

Zevitz, R. G. (1987). Police civil liability and the law of high speed pursuit. Marquette Law Review, 70, 237-284. 


\section{CURRICULUM VITAE}

Frederick A. Williams Jr.

1235 Denney Drive

Lawrenceburg, KY 40342

fwilliamsjr@roadrunner.com

(502) 600-4642

\section{EDUCATION}

2012-Current Doctor of Philosophy, Criminal Justice

University of Louisville, Louisville, Kentucky

Dissertation Chair: Dr. George Higgins, Ph.D.

2000 Master of Science, Justice Administration

University of Louisville, Louisville, Kentucky

1995 Bachelor of Science, Criminal Justice; Tennessee State University, Nashville, Tennessee

\section{ACADEMIC APPOINTMENTS}

Jefferson Community and Technical College, Department of Criminal Justice 2007 - 2016 Adjunct Instructor

Kentucky State University, Social Work and Criminal Justice Department 2000 - 2005 Adjunct Instructor

\section{TEACHING EXPERIENCE}

Prior Courses:

Introduction to Criminal Justice * +

Introduction to Law Enforcement $*+$

Criminal Justice Administration + 
Police Legitimacy

Crime Prevention

Procedural Justice

Criminological Theory

Police Ethics

\author{
* Collegiate Online Development \\ + Collegiate Course Created \\ $\sim$ Kentucky State Police Training Course
}

INVITED PRESENTATIONS AND LECTURES

Numerous recruitment presentations to collegiate and community groups.

\title{
SERVICE
}

Professional Service

2016 - 2017 International Board Member, American Association of Motor Vehicle Administrators (AAMVA)

2012 - 2016 Committee Member, Driver Standing Committee, American Association of Motor Vehicle Administrators (AAMVA)

2012 - 2013 Committee Member, Region 2 Conference Planning Committee, A merican Association of Motor Vehicle Administrators (AAMVA)

Community Service

2012 Youth Coach, Anderson County Recreational Youth Basketball

$2007-2010$ Youth Coach, Anderson County Youth Soccer Association

PROFESSIONAL AFFILIATIONS

1998 - Present Kentucky State Police Professional Association

Life Member Phi Beta Sigma Fraternity Incorporated 
2016 - Present $\quad$ Commander - Major, Division of Operational Support, Administrative Division, Kentucky State Police Department

2015 - 2016 Commander - Captain, Academy Branch, Administrative Division, Kentucky State Police Department

$2013-2015 \quad$ Commander - Captain, Campbellsburg Post 5, Operations Division, Kentucky State Police Department

2010 - $2013 \quad$ Commander - Captain, Driver Testing Branch, Administrative Division, Kentucky State Police Department

$2008-2010$ Investigative Lieutenant, Frankfort Post 12, Operations Division, Kentucky State Police Department

2008 - $2008 \quad$ Operations Lieutenant, Campbellsburg Post 5, Operations

Division, Kentucky State Police Department

2006 - 2008 Sergeant, Driver Testing Branch, Administrative Division, Kentucky State Police Department

2004 - $2006 \quad$ Sergeant, Frankfort Post 12, Operations Division, Kentucky State Police Department

$2004-2004 \quad$ Sergeant, Campbellsburg Post 5, Operations Division, Kentucky State Police Department

$2003-2004 \quad$ Senior Trooper, Frankfort Post 12, Operations Division, Kentucky State Police Department

2001 - $2003 \quad$ Commander - Trooper, Recruitment Branch, Administrative Division, Kentucky State Police Department

$1998-2001 \quad$ Trooper, Morehead Post 8, Operations Division, Kentucky State Police Department

1996 - 1998 Driver Test Administrator I, Driver Testing Branch, Administrative Division, Kentucky State Police Department 
1995 - 1996 Correctional Officer, River City Correctional Center, Louisville Kentucky

1995 - $1998 \quad$ Varsity Football Coach, Western High School, Louisville Kentucky

\section{CERTIFICATIONS}

Peace Officer, Kentucky Law Enforcement Council

Certificate of Management Fundamentals (CMF), Governor Office of Technology

Certified Public Manager (CPM), Governor Office of Technology

Certified Collision Reconstructionist

National American Standards Level 1 Certification

AWARDS AND HONORS

2008 Citation for Bravery Kentucky State Police Department

1998 Cadet Fitness Award Kentucky State Police Academy

\section{ADDITIONAL EDUCATION}

2005 School of Police Staff and Command, Northwestern University, Class Vice President (10 weeks)

2001 - 2005 Governor's Minority Management Training Program, Kentucky State Government

1998 Trooper Cadet Training-Class 75, Kentucky State Police Department (22 weeks)

RESEARCH FOCUS

Law Enforcement

Program Evaluation within Law Enforcement Agencies 


\section{REFERENCES}

Available upon request

SOFTWARE EXPERIENCE

SPSS

UPDATED

April, 2019 